\title{
LA VERSIFICACIÓN DRAMÁTICA ESPAÑOLA EN EL PERÍODO $1587-1610$
}

En 1925 publicó S. Griswold Morley un importante artículo sobre las formas estróficas en el teatro anterior a Lope de Vega ${ }^{1}$. Ahora que poseemos un verdadero cúmulo de materiales sobre el período lopesco, trataré de hacer, en el presente artículo, un estudio análogo acerca de la versificación en los años 1587-1610.

A esta época pertenecen 131 comedias auténticas de Lope ${ }^{2}$, con termini ad quem seguros, y 52 de otros dramaturgos que tienen también, por razones de crítica interna o externa, un terminus ad quem comprobado ${ }^{3}$. Los datos de ocho de las comedias (núms. 7, $26,38,53,55,56,66$ y 71 del Cuadro A, que damos a continuación) provienen de nuestra Chronology, "Table III" 4 .

${ }^{1}$ S. G. Morlex, "Strophes in the Spanish drama before Lope de Vega", $H M P$, t. $1,505-531$.

"En nuestra Chronology of Lope de Vega's comedias, "Table I", se enumeran 126 (núms. 2-127), de las cuales restamos cuatro: La suerte de los reyes, obra incompleta, Los Guzmanes de Toral, dudosa (cf. "Addenda...", HR, ${ }_{15}$, ${ }_{1947}$, p. 57, núm. 78), y El lacayo fingido y El principe melancólico, sobre cuyos textos ha suscitado graves dudas J. H. ArJONA, $S P h, 5^{1}$ (1954), 42-53, y $H R$, 24 (1956), 42-49. Quedan, pues, 122 comedias, a las cuales añadimos nueve: El principe inocente (1590), El amor desatinado (1597) y Viuda, casada y doncella (1597), incluidas con sus fechas en las copias de autógrafos de Lope hechas por Gálvez en 1762; La doncella Teodor, fechada en 1608-1o por W. L. Fichter, HR, 9 (1941), 86-87; y cinco comedias de la "Table II" de la Chronology, cuyos termini ad quem nos proporciona SAN Román: Del mal lo menos, Los españoles en Flandes, El halcón de Federico, El mayordomo de la duquesa de Amalfi y La obediencia laureada.

"Con tres excepciones: El curioso impertinente y el Don Quijote de la Mancha de Guillén de Castro, y el núm. 39, cuyo terminus ad quem es 1601 sólo en caso de que Tárrega sea el autor; sea como fuere, es indudablemente anterior a 1611 .

"Empleamos las siguientes abreviaturas: "Add": "Addenda to the Chronology of Lope de Vega's comedias", HR, 15 (1947), 49-71.-Amezúa: A. G. DE AмezúA, Una colección manuscrita y desconocida de comedias de Lope de Vega Carpio, Madrid, 1945-Chron.: S. Griswold Morley \& Courtney BruerToN, The chronology of Lope de Vega's comedias, New York, 1940.-Doce com.: Doce comedias famosas de quatro poetas naturales de la... ciudad de Va. lencia, Valencia, 1608.-Fiestas: Fiestas que... Valencia ha hecho por la beatificación del santo fray Luis Bertrán, Valencia, 1608.-Flor: Flor de comedias de España de diferentes autores... Quinta parte, Madrid, 1615-Gálvez: copia de autógrafos de Lope hecha por Ignacio de Gálvez en 1762 (cf. Amezúa).-Ju. 
El Cuadro A incluye 44 comedias de Lope: 17 de ellas, procedentes de la colección de Gálvez, tienen un orden cronológico seguro (dos no se han publicado); los termini ad quem de otras dos (núms. 1 y 2) son también seguros; y las 25 restantes nos suministran muestras de la versificación de Lope en el transcurso de los años (las hemos elegido de preferencia entre las autógrafas, para hacer más cómoda la comparación con las obras de los demás dramaturgos) .

Los autores de las otras 52 comedias de nuestro Cuadro A son los siguientes: Tárrega ( 10 comedias, y una más de atribución no muy segura), Aguilar (6), Castro (6), Mira de Amescua (4, y una dudosa), Vélez de Guevara (3), Salustio del Poyo (3), Grajal (2), Beneyto, Boyl, Castellano, Mejía de la Cerda, Mesa, Quirós, Remón, Sánchez y Valdivielso (una comedia cada uno). Las siete restantes son anónimas (núms. $7,26,55,5^{6}$ y 66 , cuyos datos proceden de la Chronology, "Table III", y núms. $4^{8}$ y 71 , cuyas cifras se publican ahora por vez primera).

Lí́: Poetas dramáticos valencianos, editados por Eduardo Juliá Martínez, 2 ts., Madrid, 1929-MÉrimée: Henri Mérimée, L'art dramatique à Valencia, Toulouse, 1913.-San Román: Francisco de B. SAn Román, lope de Vega, los cómicos toledanos y el poeta sastre, Madrid, 1935- Seis com.: Seis comedias de Lope de Vega Carpio y de otros autores, Lisboa, 1603.

Otras abreviaturas:

ant. = antes de;

bl. can = canción, estancia lírica en que sólo los dos últimos versos de cada estrofa van rimados;

can = canción, estancia lírica;

déc = décimas;

diál. = diálogo;

interr. = interrumpido;

irr. = irregulares;

lir = liras;

m. ad. = parlamento largo dirigido a otra persona;

m. $\mathrm{l}$. = monólogo lírico;

m. n. = monólogo narrativo;

oct $=$ octavas;

par = pareados;

qui $=$ quintillas;

red $=$ redondillas;

rom = romance;

ses $=$ sestinas italianas;

sil = silva;

son = soneto;

sue $=$ versos sueltos;

ter = tercetos;

$6-\mathrm{s}=$ hexasilabos;

8 -s $=$ octosílabos.

En cuanto a los tipos de sonetos $(A, B \ldots)$, de quintillas $(1,2,3 \ldots)$, etc., véase nuestra Chronology. - En las Notas al Cuadro $\mathrm{A}$, cuando no se indica a qué uso se destinan los distintos metros, entiéndase que es el diálogo. 
CUADRO A

COMEDIAS FECHADAS EN ORDEN CRONOLÓGICO

\begin{tabular}{|c|c|c|c|c|c|c|c|c|c|c|c|c|}
\hline Fecha & Autor & $\begin{array}{c}\text { Titulo y } \\
\text { numero de versos }\end{array}$ & red & $q u i$ & rom & oct & son & ter & lir & sue & otros & $\begin{array}{c}\text { Comienzos y fina- } \\
\text { les de acto }\end{array}$ \\
\hline $1587-88$ & lope & $\begin{array}{l}\text { 1. Celos de Roda- } \\
\text { monte } 3175\end{array}$ & $\begin{array}{r}1180 \\
37.1\end{array}$ & $\begin{array}{r}880 \\
27.8\end{array}$ & & $\begin{array}{r}216 \\
6.8\end{array}$ & & $\begin{array}{c}574 \\
18 .\end{array}$ & $\begin{array}{r}234 \\
7.4\end{array}$ & $\begin{array}{r}65 \\
2 .\end{array}$ & $\begin{array}{r}26 \\
\quad .8\end{array}$ & $\begin{array}{l}\text { qui-red, red-red, } \\
\text { sue-oct }\end{array}$ \\
\hline $1587 \cdot 88$ & Lope & $\begin{array}{l}\text { 2. Ferials de } \mathrm{Ma-} \\
\text { drid }\end{array}$ & $\begin{array}{r}223^{6} \\
69 \cdot 2\end{array}$ & $\begin{array}{r}205 \\
6.3\end{array}$ & & $\begin{array}{r}40 \\
1.2\end{array}$ & & $\begin{array}{r}5^{64} \\
17 \cdot 4\end{array}$ & & $\begin{array}{r}174 \\
5 \cdot 4\end{array}$ & $\begin{array}{r}12 \\
.4\end{array}$ & $\begin{array}{l}\text { red-red, ter-red, } \\
\text { red-red }\end{array}$ \\
\hline 1590 & Lope & $\begin{array}{lr}\text { 3. Principe ino- } \\
\text { cente } & 2529\end{array}$ & $\begin{array}{r}177^{2} \\
70\end{array}$ & $\begin{array}{r}140 \\
5.5\end{array}$ & & $\begin{array}{r}5^{6} \\
2.2\end{array}$ & $\begin{array}{r}14 \\
.6\end{array}$ & $\begin{array}{r}420 \\
16.6\end{array}$ & & $\begin{array}{r}127 \\
5\end{array}$ & & $\begin{array}{l}\text { red-red, ter-red, } \\
\text { red-ter }\end{array}$ \\
\hline $159^{\prime \prime}$ & Lope & $\begin{array}{l}\text { 4. Carlos el perse- } \\
\text { guido } \\
3527\end{array}$ & $\begin{array}{r}1680 \\
47.6\end{array}$ & $\begin{array}{r}85^{0} \\
24 \cdot 1\end{array}$ & & $\begin{array}{r}328 \\
9 \cdot 3\end{array}$ & $\begin{array}{r}14 \\
.4\end{array}$ & $\begin{array}{r}271 \\
7 \cdot 7\end{array}$ & & $\begin{array}{r}3^{84} \\
10.9\end{array}$ & & $\begin{array}{l}\text { red-sue, qui-oct, } \\
\text { red-qui }\end{array}$ \\
\hline $15^{88-91}$ & Quirós & $\begin{array}{lr}\text { 5. Famosa toleda- } \\
\text { na } & 3^{165}\end{array}$ & $\begin{array}{r}3060 \\
95.8\end{array}$ & & & $\begin{array}{r}8 \\
.2\end{array}$ & & & & $\begin{array}{l}97 \\
3 .\end{array}$ & & $\begin{array}{l}\text { red, sue-oct, } \\
\text { red }\end{array}$ \\
\hline $159^{0-9}{ }^{1}$ & I árrega & $\begin{array}{l}\text { 6. Prado de Va- } \\
\text { loncia }\end{array}$ & $\begin{array}{r}2428 \\
62.6\end{array}$ & $\begin{array}{r}1015 \\
26.1\end{array}$ & $\begin{array}{r}64 \\
1.6\end{array}$ & $\begin{array}{r}296 \\
7.6\end{array}$ & $\begin{array}{r}14 \\
.4\end{array}$ & & & $\begin{array}{r}64 \\
1.6\end{array}$ & & $\begin{array}{l}\text { red-red, qui-red, } \\
\text { red-red }\end{array}$ \\
\hline $1593^{\circ}$ & $?$ & $\begin{array}{l}\text { 7. Burlas y enre- } \\
\text { dos de Benito } \\
\mathbf{2 5 0 0}\end{array}$ & $\begin{array}{r}219^{2} \\
87 \cdot 7\end{array}$ & & & $\begin{array}{r}32 \\
1 \cdot 3\end{array}$ & & $\begin{array}{r}215 \\
8.6\end{array}$ & & $\begin{array}{r}61 \\
2.3\end{array}$ & & $\begin{array}{l}\text { red-red; red-red; } \\
\text { red-red }\end{array}$ \\
\hline 1593 & Lope & $\begin{array}{l}\text { 8. Caballero del } \\
\text { milagro } \\
3^{001}\end{array}$ & $\begin{array}{r}2324 \\
77 \cdot 4\end{array}$ & & & $\begin{array}{r}184 \\
6.1\end{array}$ & $3^{1}$ & & $\begin{array}{r}15^{6} \\
5.2\end{array}$ & $\begin{array}{r}306 \\
10.2\end{array}$ & & $\begin{array}{l}\text { red-oct; red-red; } \\
\text { red-red }\end{array}$ \\
\hline
\end{tabular}




\begin{tabular}{|c|c|c|c|c|c|c|c|c|c|c|c|c|}
\hline Fecha & Autor & $\begin{array}{c}\text { Titulo y } \\
\text { nuimero de versos }\end{array}$ & $r e d$ & $q u i$ & $\mathrm{rom}$ & $o c t$ & son & ter & lir & sue & otros & $\begin{array}{c}\text { comienzos y fina } \\
\text { les de acto }\end{array}$ \\
\hline 1593 & Lope & $\begin{array}{lr}\text { 9. Favor agrade- } \\
\text { cido } & 3126\end{array}$ & $\begin{array}{r}173^{6} \\
55 \cdot 5\end{array}$ & $\begin{array}{r}425 \\
13.6\end{array}$ & $\begin{array}{r}184 \\
5.8\end{array}$ & $\begin{array}{r}224 \\
7.2\end{array}$ & $\begin{array}{l}14 \\
.4\end{array}$ & $\begin{array}{r}134 \\
4 \cdot 3\end{array}$ & $\begin{array}{r}90 \\
2.9\end{array}$ & $\begin{array}{r}319 \\
10.2\end{array}$ & & $\begin{array}{l}\text { red-sue?, qui-sue, } \\
\text { sue-red }\end{array}$ \\
\hline $1 ! 994$ & Lope & $\begin{array}{l}\text { 10. Maestro de } \\
\text { danzar } \\
3042\end{array}$ & $\begin{array}{r}2196 \\
72.2\end{array}$ & $\begin{array}{c}35 \\
1.1\end{array}$ & $\begin{array}{r}116 \\
4\end{array}$ & $\begin{array}{r}104 \\
3 \cdot 4\end{array}$ & $\begin{array}{l}42 \\
1.3\end{array}$ & & $\begin{array}{c}108 \\
3 \cdot 5\end{array}$ & $\begin{array}{l}288 \\
9 \cdot 5\end{array}$ & $\begin{array}{l}\text { red \& qui } \\
1535 \%\end{array}$ & $\begin{array}{l}\text { red-oct, red-sue, } \\
\text { red-red }\end{array}$ \\
\hline 1594 & Lope & $\begin{array}{l}\text { 11. I.eal criado } \\
33^{87}\end{array}$ & $\begin{array}{r}1588 \\
4^{6.9}\end{array}$ & $\begin{array}{l}1030 \\
3^{0.4}\end{array}$ & $\begin{array}{l}120 \\
3.5\end{array}$ & $\begin{array}{r}13^{6} \\
4 .\end{array}$ & $\begin{array}{l}56 \\
1.6\end{array}$ & & & $\begin{array}{r}457 \\
13 \cdot 5\end{array}$ & & $\begin{array}{l}\text { red-red, red-sue, } \\
\text { red-qui }\end{array}$ \\
\hline 1594 & Lope & $\begin{array}{lr}\text { 12. San Segundo } \\
\text { de Avila } 2923\end{array}$ & $\begin{array}{r}1184 \\
40.5\end{array}$ & $\begin{array}{r}935 \\
3^{1} \cdot 9\end{array}$ & $\begin{array}{r}284 \\
9 \cdot 7\end{array}$ & $\begin{array}{r}160 \\
5 \cdot 4\end{array}$ & $\begin{array}{l}3 \mathrm{I} \\
1.2\end{array}$ & $\begin{array}{r}82 \\
2.8\end{array}$ & $\begin{array}{r}72 \\
2.5\end{array}$ & $\begin{array}{r}175 \\
6 .\end{array}$ & & $\begin{array}{l}\text { red-oct, oct-qui, } \\
\text { qui-oct }\end{array}$ \\
\hline 1594 & Lope & $\begin{array}{lr}\text { 13. Laura } & \text { perse- } \\
\text { guida } & 3203\end{array}$ & $\begin{array}{l}1688 \\
52 \cdot 7\end{array}$ & $\begin{array}{r}700 \\
21.8\end{array}$ & $\begin{array}{r}7^{6} \\
2.4\end{array}$ & $\begin{array}{r}160 \\
5\end{array}$ & $\begin{array}{r}56 \\
1.7\end{array}$ & & $\begin{array}{r}78 \\
2.4\end{array}$ & $\begin{array}{r}445 \\
13.9\end{array}$ & & $\begin{array}{l}\text { red-oct, red-sue, } \\
\text { qui-qui }\end{array}$ \\
\hline $1588-95$ & Lope & $\begin{array}{l}\text { 14. Hijo venturo- } \\
\text { so }\end{array}$ & $\begin{array}{r}35^{\circ 8} \\
97 \cdot 9\end{array}$ & & $\begin{array}{r}76 \\
2.1\end{array}$ & & & & & & & red, red, red-red \\
\hline 1596 & Lope & $\begin{array}{l}\text { 15. Marqués de } \\
\text { Mantua } 287^{6}\end{array}$ & $\begin{array}{c}892 \\
31\end{array}$ & $\begin{array}{c}80_{5} \\
28 .\end{array}$ & $\begin{array}{r}464 \\
16.1\end{array}$ & $\begin{array}{r}328 \\
11.4\end{array}$ & $\begin{array}{l}28 \\
1 .\end{array}$ & & $\begin{array}{r}13^{8} \\
4.8\end{array}$ & $\begin{array}{r}78 \\
2.7\end{array}$ & $\begin{array}{r}\text { ses } 39 \\
1.3 \\
\text { bl. can } \\
1043.6 \%\end{array}$ & $\begin{array}{l}\text { qui-sue, red-rom, } \\
\text { red-oct }\end{array}$ \\
\hline 1596 & Lope & $\begin{array}{r}\text { 16. Francesilla } \\
2829\end{array}$ & $\begin{array}{c}223^{6} \\
79\end{array}$ & $\begin{array}{c}100 \\
355\end{array}$ & $\begin{array}{r}122 \\
4 \cdot 3\end{array}$ & $\begin{array}{l}4^{8} \\
1.7\end{array}$ & & $\begin{array}{r}70 \\
2.5\end{array}$ & & $\begin{array}{r}253 \\
8.9\end{array}$ & & $\begin{array}{l}\text { red-red, red-red, } \\
\text { red-red }\end{array}$ \\
\hline 1596 & Lope & $\begin{array}{l}\text { 17. Remedio en } \\
\text { la desdicha } 2981\end{array}$ & $\begin{array}{r}1676 \\
5^{6.2}\end{array}$ & $\begin{array}{r}310 \\
10.4\end{array}$ & $\begin{array}{r}3^{16} \\
10.6\end{array}$ & $\begin{array}{r}120 \\
4 .\end{array}$ & $\begin{array}{r}28 \\
.9\end{array}$ & $\begin{array}{r}42 \\
1.4\end{array}$ & & $\begin{array}{r}232 \\
7.8\end{array}$ & $\begin{array}{rr}\text { dec } \quad 60 \\
\\
\text { can } \quad 157 \\
\\
\text { ses } \quad 3.3 \\
\\
\\
1.3\end{array}$ & $\begin{array}{l}\text { can-can, red-sue, } \\
\text { oct-red }\end{array}$ \\
\hline
\end{tabular}




\begin{tabular}{|c|c|c|c|c|c|c|c|c|c|c|c|c|}
\hline Fecha & Autor & $\begin{array}{c}\text { Titulo y } \\
\text { número de versos }\end{array}$ & red & $q u i$ & rom & oct & son & ter & lir & sue & otros & $\begin{array}{c}\text { comienzos y fina. } \\
\text { les de acto }\end{array}$ \\
\hline 1596 & Lope & $\begin{array}{l}\text { 18. Bella mal ma- } \\
\text { ridada } 279^{2}\end{array}$ & $\begin{array}{r}2428 \\
86.9\end{array}$ & $\begin{array}{r}220 \\
7 \cdot 9\end{array}$ & & $\begin{array}{r}144 \\
5 \cdot 1\end{array}$ & & & & & & $\begin{array}{l}\text { red, qui-red, } \\
\text { red-red }\end{array}$ \\
\hline $159^{6}$ & Lope & $\begin{array}{l}\text { 19. Comendado- } \\
\text { res de Córdoba } \\
3^{013}\end{array}$ & $\begin{array}{r}1888 \\
63 .\end{array}$ & $\begin{array}{r}625 \\
20.7\end{array}$ & $\begin{array}{r}80 \\
2.6\end{array}$ & $\begin{array}{r}80 \\
2.6\end{array}$ & $\begin{array}{r}115 \\
3.8\end{array}$ & & & $\begin{array}{c}18_{5}^{5} \\
6 .\end{array}$ & déc $\begin{array}{l}4^{\circ} \\
1.3\end{array}$ & $\begin{array}{l}\text { qui-red, red-red, } \\
\text { red-red }\end{array}$ \\
\hline 1597 & Lope & $\begin{array}{l}\text { 20. Amor des- } \\
\text { atinado }\end{array}$ & $\begin{array}{l}15^{64} \\
50.2\end{array}$ & $\begin{array}{l}530 \\
17 .\end{array}$ & $\begin{array}{r}176 \\
5.6\end{array}$ & $\begin{array}{r}192 \\
6.2\end{array}$ & $\begin{array}{r}42 \\
1.3\end{array}$ & & $\begin{array}{r}222 \\
7.1\end{array}$ & $\begin{array}{r}259 \\
8.3\end{array}$ & $\begin{array}{r}130 \\
4.2\end{array}$ & $\begin{array}{l}\text { qui-red, oct-qui, } \\
\text { lir-red }\end{array}$ \\
\hline 1597 & Lope & $\begin{array}{ll}\text { 21. Imperial de } \\
\text { Otón } & 27^{\circ} 9\end{array}$ & $\begin{array}{r}137^{6} \\
5^{0.8}\end{array}$ & $\begin{array}{c}49^{\circ} \\
18 .\end{array}$ & $\begin{array}{r}310 \\
11.4\end{array}$ & $\begin{array}{r}184 \\
6.8\end{array}$ & & $\begin{array}{c}55 \\
2 .\end{array}$ & & $\begin{array}{r}235 \\
8.7\end{array}$ & $\begin{array}{r}\text { bl. can } \\
592.2 \%\end{array}$ & $\begin{array}{l}\text { red-sue, red-sue, } \\
\text { red-qui }\end{array}$ \\
\hline 1597 & Lope & $\begin{array}{l}\text { 22. Viuda, casada } \\
\text { y doncella } 2973\end{array}$ & $\begin{array}{r}1172 \\
39 \cdot 4\end{array}$ & $\begin{array}{r}1180 \\
39.7\end{array}$ & $\begin{array}{r}256 \\
8.6\end{array}$ & & & & & $\begin{array}{r}261 \\
8.8\end{array}$ & $\begin{array}{r}\text { bl. can } \\
1043.5 \%\end{array}$ & $\begin{array}{l}\text { qui-qui, qui-qui, } \\
\text { qui-qui }\end{array}$ \\
\hline 1597 & Lope & $\begin{array}{l}\text { 23. Torneos } d e \\
\text { Aragón } 3122\end{array}$ & $\begin{array}{r}828 \\
26.5\end{array}$ & $\begin{array}{r}1610 \\
51.6\end{array}$ & $\begin{array}{r}282 \\
9\end{array}$ & $\begin{array}{r}64 \\
2 .\end{array}$ & $\begin{array}{r}28 \\
.9\end{array}$ & & & $\begin{array}{r}142 \\
4.6\end{array}$ & 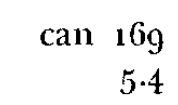 & $\begin{array}{l}\text { qui-qui, qui-qui, } \\
\text { qui-red }\end{array}$ \\
\hline${ }_{15} 9^{8 ?-99}$ & Castro & $\begin{array}{lr}\text { 24. A mor cons- } \\
\text { tante } & 3476\end{array}$ & $\begin{array}{r}2444 \\
70.3\end{array}$ & $\begin{array}{c}340 \\
9.8\end{array}$ & $\begin{array}{r}248 \\
7 \cdot 1\end{array}$ & $\begin{array}{r}64 \\
1.8\end{array}$ & & $\begin{array}{r}114 \\
3 \cdot 3\end{array}$ & $\begin{array}{r}24 \\
.7\end{array}$ & $\begin{array}{r}76 \\
2.2\end{array}$ & $\begin{array}{rr}\text { déc } \quad 4^{\circ} \\
\\
1.1 \\
\text { can } \quad 126 \\
& 3.6\end{array}$ & $\begin{array}{l}\text { red-ter, qui-red, } \\
\text { qui-red }\end{array}$ \\
\hline ca. 1599 & Castro & $\begin{array}{l}25 . \text { Desengaño di- } \\
\text { choso }\end{array}$ & $\begin{array}{r}1752 \\
5^{8.7}\end{array}$ & $\begin{array}{r}560 \\
18.8\end{array}$ & $\begin{array}{r}126 \\
4.2\end{array}$ & $\begin{array}{c}32 \\
1.1\end{array}$ & & $\begin{array}{r}166 \\
5.6\end{array}$ & $\begin{array}{r}54 \\
1.8\end{array}$ & $\begin{array}{r}194 \\
4.5\end{array}$ & 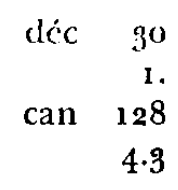 & $\begin{array}{l}\text { qui-red, red-ter, } \\
\text { red-red }\end{array}$ \\
\hline 1599 & $?$ & $\begin{array}{l}\text { 26. Cautivos de } \\
\text { Argel } 2860\end{array}$ & $\begin{array}{r}2100 \\
73.4\end{array}$ & $\begin{array}{l}90 \\
3 \cdot 1\end{array}$ & $\begin{array}{r}296 \\
10.3\end{array}$ & $\begin{array}{r}4^{\circ} \\
1.4\end{array}$ & $\begin{array}{c}28 \\
1 .\end{array}$ & $\begin{array}{r}52 \\
1.8\end{array}$ & & $\begin{array}{r}254 \\
8.9\end{array}$ & & $\begin{array}{l}\text { red-sue, qui-red, } \\
\text { ter-rom }\end{array}$ \\
\hline
\end{tabular}




\begin{tabular}{|c|c|c|c|c|c|c|c|c|c|c|c|c|}
\hline Fecha & Autor & $\begin{array}{c}\text { Tilulo y } \\
\text { numero de versos }\end{array}$ & red & $q u i$ & rom & $o c t$ & son & ter & lir & sue & otros & $\begin{array}{c}\text { comienzos y fina } \\
\text { les de acto }\end{array}$ \\
\hline 1599 & Lope & $\begin{array}{lr}\text { 27. Tirano } & \text { casti. } \\
\text { gado } & 3^{07} 6\end{array}$ & $\begin{array}{r}1008 \\
32.7\end{array}$ & $\begin{array}{r}1160 \\
37.8\end{array}$ & $\begin{array}{l}514 \\
16.7\end{array}$ & $\begin{array}{r}72 \\
2.3\end{array}$ & $\begin{array}{r}2.8 \\
.9\end{array}$ & $\begin{array}{r}77 \\
2.5\end{array}$ & & $\begin{array}{l}167 \\
5 \cdot 4\end{array}$ & $\begin{array}{ll}\text { déc } & 50 \\
& 1.6\end{array}$ & $\begin{array}{l}\text { red-qui, qui-rom, } \\
\text { red-qui }\end{array}$ \\
\hline 1599 & Lope & $\begin{array}{cc}\text { 28. Blasón de los } \\
\text { Chaves } & 3^{122}\end{array}$ & $\begin{array}{c}600 \\
19 .\end{array}$ & $\begin{array}{l}1615 \\
51.6\end{array}$ & $\begin{array}{r}4^{6} 4 \\
14.8\end{array}$ & $\begin{array}{c}192 \\
6.1\end{array}$ & $\begin{array}{r}28 \\
.9\end{array}$ & $\begin{array}{r}99 \\
3.2\end{array}$ & & $\begin{array}{r}130 \\
4.2\end{array}$ & & $\begin{array}{l}\text { oct-son, red-son, } \\
\text { suc-rom }\end{array}$ \\
\hline 1599 & Lope & $\begin{array}{l}\text { 29. A migo por } \\
\text { fuerza } \\
343^{1}\end{array}$ & $\begin{array}{r}1392 \\
4^{0.6}\end{array}$ & $\begin{array}{r}1160 \\
33.8\end{array}$ & $\begin{array}{r}268 \\
7.8\end{array}$ & $\begin{array}{r}17^{6} \\
5.1\end{array}$ & $\begin{array}{r}30 \\
.8\end{array}$ & $\begin{array}{l}49 \\
1.4\end{array}$ & & $\begin{array}{r}279 \\
8.1\end{array}$ & $\begin{array}{r}\text { bl. can } \\
76 \quad 2.3 \%\end{array}$ & $\begin{array}{l}\text { qui-qui, bl. canc- } \\
\text { red, red-red }\end{array}$ \\
\hline 1599 & Lope & $\begin{array}{l}\text { 30. Varona caste- } \\
\text { llana } \\
320_{5}\end{array}$ & $\begin{array}{r}1608 \\
50.2\end{array}$ & $\begin{array}{r}655 \\
20.4\end{array}$ & $\begin{array}{r}318 \\
9.9\end{array}$ & $\begin{array}{r}200 \\
6.2\end{array}$ & $\begin{array}{l}42 \\
1.3\end{array}$ & $\begin{array}{r}110 \\
3.4\end{array}$ & & $\begin{array}{r}272 \\
8.6\end{array}$ & & $\begin{array}{l}\text { red-qui, ter-red, } \\
\text { red-rom }\end{array}$ \\
\hline 1599 & Lope & $\begin{array}{l}\text { 31. Pobrezas de } \\
\text { Reinaldos } \quad 3^{2} 76\end{array}$ & $\begin{array}{r}680 \\
20.7\end{array}$ & $\begin{array}{r}1300 \\
39 \cdot 7\end{array}$ & $\begin{array}{l}654 \\
20 .\end{array}$ & $\begin{array}{r}33^{6} \\
10.2\end{array}$ & & $\begin{array}{r}197 \\
6 .\end{array}$ & & $\begin{array}{r}109 \\
3 \cdot 3\end{array}$ & & $\begin{array}{l}\text { qui-qui, red-qui, } \\
\text { qui-rom }\end{array}$ \\
\hline $\begin{array}{l}\text { ant. agosto } \\
1600\end{array}$ & Tárrega & $\begin{array}{l}\text { 32. Sangre leal } \\
\qquad 3^{2} 4^{2}\end{array}$ & & $\begin{array}{r}3170 \\
97.8\end{array}$ & $\begin{array}{r}72 \\
2.2\end{array}$ & & & & & & & rom-qui, qui, qui \\
\hline ant. 1600 & Beneyto & $\begin{array}{l}\text { 33. Hijo obedien } \\
\text { te } 3121\end{array}$ & $\begin{array}{r}276 \\
8.8\end{array}$ & $\begin{array}{r}26.55 \\
85.1\end{array}$ & $\begin{array}{r}124 \\
4\end{array}$ & & $\begin{array}{r}14 \\
.4\end{array}$ & $\begin{array}{r}5^{2} \\
1.7\end{array}$ & & & & $\begin{array}{l}\text { qui-qui, red-qui, } \\
\text { qui-qui }\end{array}$ \\
\hline 1600 & Lope & $\begin{array}{l}\text { 34. Embustes de } \\
\text { Celauro } 317^{2}\end{array}$ & $\begin{array}{r}1508 \\
47 \cdot 5\end{array}$ & $\begin{array}{l}730 \\
23 .\end{array}$ & $\begin{array}{r}25,0 \\
7.9\end{array}$ & $\begin{array}{r}152 \\
4.8\end{array}$ & $\begin{array}{l}70 \\
2.2\end{array}$ & & $\begin{array}{r}108 \\
3.4\end{array}$ & $\begin{array}{r}259 \\
8.2\end{array}$ & $\begin{array}{cc}\text { 8-s } & \text { par } \\
95 & 3 \%\end{array}$ & $\begin{array}{l}\text { qui-red, sue-qui, } \\
\text { lir-red }\end{array}$ \\
\hline 1600 & Lope & $\begin{array}{l}\text { 35. Contienda de } \\
\text { Garcia } \quad 2928\end{array}$ & $\begin{array}{r}7^{6} 6 \\
26.1\end{array}$ & $\begin{array}{r}79^{\circ} \\
26.9\end{array}$ & $\begin{array}{r}622 \\
21.2\end{array}$ & $\begin{array}{r}33^{6} \\
11.5\end{array}$ & $\begin{array}{r}14 \\
.5\end{array}$ & $\begin{array}{r}49 \\
1.7\end{array}$ & & $\begin{array}{r}353 \\
12 .\end{array}$ & & $\begin{array}{l}\text { qui-sue, qui-red, } \\
\text { ter-oct }\end{array}$ \\
\hline 1600 & Lope & $\begin{array}{ll}3^{6 .} \text { Ingrato } & \text { arre } \\
\text { pentido } & 3^{189}\end{array}$ & $\begin{array}{r}1388 \\
43.5\end{array}$ & $\begin{array}{r}1080 \\
33.9\end{array}$ & $\begin{array}{r}45^{8} \\
14 \cdot 4\end{array}$ & $\begin{array}{c}96 \\
3 .\end{array}$ & $\begin{array}{r}28 \\
.9\end{array}$ & & $\begin{array}{r}24 \\
7\end{array}$ & $\begin{array}{r}115 \\
3.6\end{array}$ & & $\begin{array}{l}\text { red-sue, qui-red, } \\
\text { qui-rom }\end{array}$ \\
\hline 1600 & Lope & $\begin{array}{l}\text { 37. Benavides } \\
3503\end{array}$ & $\begin{array}{r}988 \\
28.2\end{array}$ & $\begin{array}{r}1635 \\
4^{6.7}\end{array}$ & $\begin{array}{r}4^{80} \\
13.7\end{array}$ & & $\begin{array}{c}70 \\
2 .\end{array}$ & & & $\begin{array}{r}33^{\circ} \\
9 \cdot 4\end{array}$ & & $\begin{array}{l}\text { qui-qui, qui-red, } \\
\text { qui-red }\end{array}$ \\
\hline
\end{tabular}




\begin{tabular}{|c|c|c|c|c|c|c|c|c|c|c|c|c|}
\hline Fecha & Autor & $\begin{array}{l}\text { Titulo y } \\
\text { numero de versos }\end{array}$ & red & $q u i$ & rom & ort & son & ter & lir & sue & otros & $\begin{array}{c}\text { comienzos y fina- } \\
\text { les de acto }\end{array}$ \\
\hline $1599^{-1601}$ & Vélez & $\begin{array}{l}\text { 38. Prodigioso } \\
\text { principe } 43^{17} 7\end{array}$ & $\begin{array}{l}220.4 \\
51.1\end{array}$ & $\begin{array}{r}147^{\circ} \\
34\end{array}$ & $\begin{array}{r}266 \\
6.1\end{array}$ & & $\begin{array}{r}14 \\
.3\end{array}$ & $\begin{array}{r}79 \\
1.8\end{array}$ & & $\begin{array}{r}284 \\
6.6\end{array}$ & & $\begin{array}{l}\text { qui-qui, red-red, } \\
\text { sue-red }\end{array}$ \\
\hline $1595-1601 ?$ & Tárrega? & $\begin{array}{l}\text { 39. Fortuna ad- } \\
\text { aersa } \\
3281\end{array}$ & $\begin{array}{l}1204 \\
3^{6.7}\end{array}$ & $\begin{array}{r}1555 \\
47.4\end{array}$ & $\begin{array}{r}392 \\
11.9\end{array}$ & $\begin{array}{l}8 \\
.3\end{array}$ & & $\begin{array}{l}52 \\
1.5\end{array}$ & & $\begin{array}{l}70 \\
2.1\end{array}$ & & $\begin{array}{l}\text { oct-qui, red-red, } \\
\text { qui-rom }\end{array}$ \\
\hline ant. 1602 & Tárrega & $\begin{array}{l}\text { 4o. Cerco de Pa- } \\
\text { via } 404^{\circ}\end{array}$ & $\begin{array}{l}347^{2} \\
85.9\end{array}$ & $\begin{array}{r}280 \\
6.9\end{array}$ & $\begin{array}{r}248 \\
6.1\end{array}$ & & & & & & $\begin{aligned} \text { déc } & 4^{\circ} \\
& 1 .\end{aligned}$ & $\begin{array}{l}\text { qui-red, red-red, } \\
\text { red-red }\end{array}$ \\
\hline ant. 1602 & Tárrega & $\begin{array}{l}\text { 41. Suertes troca- } \\
\text { das } \\
475^{6}\end{array}$ & $\begin{array}{r}43^{6} 4 \\
9^{1.7}\end{array}$ & & $\begin{array}{r}188 \\
3.9\end{array}$ & $\begin{array}{r}176 \\
3 \cdot 7\end{array}$ & $\begin{array}{r}28 \\
.6\end{array}$ & & & & & $\begin{array}{l}\text { red-red, oct-red, } \\
\text { oct-oct }\end{array}$ \\
\hline ant. 1602 & Tárrega & $\begin{array}{l}\text { 42. Duquesa cons- } \\
\text { tante } 2745\end{array}$ & $\begin{array}{r}752 \\
27.4\end{array}$ & $\begin{array}{r}157^{\circ} \\
57.2\end{array}$ & $\begin{array}{r}9^{\circ} \\
3 \cdot 3\end{array}$ & $\begin{array}{r}72 \\
2.6\end{array}$ & $\begin{array}{r}14 \\
5\end{array}$ & $\begin{array}{c}91 \\
3 \cdot 3\end{array}$ & & $\begin{array}{l}156 \\
5 \cdot 7\end{array}$ & & $\begin{array}{l}\text { qui-qui, qui-qui, } \\
\text { qui-qui }\end{array}$ \\
\hline ant. 1602 & Tárrega & $\begin{array}{l}\text { 43. Perseguida } \\
\text { Amaltea } 3^{014}\end{array}$ & $\begin{array}{r}1460 \\
4^{8.4}\end{array}$ & $\begin{array}{r}154^{0} \\
5^{1.1}\end{array}$ & & & $\begin{array}{l}14 \\
.5\end{array}$ & & & & & $\begin{array}{l}\text { qui-qui, red-red, } \\
\text { qui-red }\end{array}$ \\
\hline ant. 1602 & Tárrega & $\begin{array}{l}\text { 44. Fundación de } \\
\text { la Orden } 3227\end{array}$ & $\begin{array}{r}128 \\
4 .\end{array}$ & $\begin{array}{r}2920 \\
90.5\end{array}$ & $\begin{array}{r}116 \\
3.5\end{array}$ & & & & & $\begin{array}{r}63 \\
1.9\end{array}$ & & $\begin{array}{l}\text { qui-qui, qui-qui, } \\
\text { qui-qui }\end{array}$ \\
\hline ant. 1602 & Tárrega & $\begin{array}{l}\text { 45. Enemiga fa- } \\
\text { vorable } \quad 3492\end{array}$ & & $\begin{array}{r}34^{20} \\
97.9\end{array}$ & & $\begin{array}{r}7^{2} \\
2.1\end{array}$ & & & & & & $\begin{array}{l}\text { oct-qui, qui, } \\
\text { qui }\end{array}$ \\
\hline ant. 1602 & Tárrega & $\begin{array}{l}\text { 46. Cerco de Ro- } \\
\text { das } \mathbf{2 8 2 1}\end{array}$ & & $\begin{array}{r}2645 \\
93.8\end{array}$ & $\begin{array}{r}176 \\
6.2\end{array}$ & & & & & & & $\begin{array}{l}\text { qui-qui, qui, } \\
\text { qui }\end{array}$ \\
\hline ant. 1602 & Tárrega & $\begin{array}{r}\text { 47. Esposo fingido } \\
2818\end{array}$ & $\begin{array}{l}788 \\
28\end{array}$ & $\begin{array}{r}19^{80} \\
7^{0.7}\end{array}$ & $\begin{array}{r}36 \\
1.3\end{array}$ & & $\begin{array}{r}14 \\
.5\end{array}$ & & & & & $\begin{array}{l}\text { red-qui, qui-red, } \\
\text { qui-qui }\end{array}$ \\
\hline ant. 1602 & $?$ & $\begin{array}{ll}4^{8 .} \text { Reina } & \text { peni- } \\
\text { tente } & 2775\end{array}$ & $\begin{array}{r}2288 \\
82.4\end{array}$ & $\begin{array}{r}100 \\
3.6\end{array}$ & $\begin{array}{r}108 \\
3.9\end{array}$ & $\begin{array}{r}64 \\
2.3\end{array}$ & & & $\begin{array}{r}3^{6} \\
1.3\end{array}$ & $\begin{array}{r}179 \\
6.5\end{array}$ & & $\begin{array}{l}\text { sue-red, red-red, } \\
\text { red-red }\end{array}$ \\
\hline
\end{tabular}




\begin{tabular}{|c|c|c|c|c|c|c|c|c|c|c|c|c|}
\hline Fecha & Autor & $\begin{array}{c}\text { Titulo y } \\
\text { numero de versos }\end{array}$ & red & $q u i$ & rom & $o c t$ & son & ter & lir & sue & otros & $\begin{array}{c}\text { comienzos y fina- } \\
\text { les de acto }\end{array}$ \\
\hline $1600-02$ & Castro & $\begin{array}{l}\text { 49. Conde Alar- } \\
\text { cos }\end{array}$ & $\begin{array}{r}2132 \\
76.8\end{array}$ & $\begin{array}{r}280 \\
10.1\end{array}$ & $\begin{array}{r}320 \\
11.5\end{array}$ & & & $\begin{array}{l}43 \\
1.5\end{array}$ & & & & $\begin{array}{l}\text { qui-red, red-ter, } \\
\text { red-rom }\end{array}$ \\
\hline 1602 & Lope & 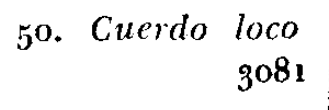 & $\begin{array}{r}1240 \\
40.2\end{array}$ & $\begin{array}{r}790 \\
25.6\end{array}$ & $\begin{array}{l}464 \\
15\end{array}$ & $\begin{array}{r}312 \\
10.1\end{array}$ & $\begin{array}{l}4^{2} \\
1.4\end{array}$ & $\begin{array}{r}67 \\
2.2\end{array}$ & & $\begin{array}{l}166 \\
5 \cdot 4\end{array}$ & & $\begin{array}{l}\text { red-red, oct-red, } \\
\text { red-rom }\end{array}$ \\
\hline 1602 & Lope & $\begin{array}{l}\text { 51. Principe des- } \\
\text { peñado } \\
3012\end{array}$ & $\begin{array}{r}15^{24} \\
50.6\end{array}$ & $\begin{array}{r}55^{\circ} \\
18.3\end{array}$ & $\begin{array}{r}390 \\
12.9\end{array}$ & $\begin{array}{r}120 \\
4 .\end{array}$ & & $\begin{array}{r}5^{8} \\
1.9\end{array}$ & $\begin{array}{r}198 \\
6.6\end{array}$ & $\begin{array}{l}172 \\
5 \cdot 7\end{array}$ & & $\begin{array}{l}\text { qui-rom, red-red, } \\
\text { qui-red }\end{array}$ \\
\hline 1602 & Mesa & $\begin{array}{ll}\text { 52. Bruto } & \text { ate- } \\
\text { niense } & 3444\end{array}$ & $\begin{array}{r}2984 \\
86.6\end{array}$ & $\begin{array}{r}100 \\
2.9\end{array}$ & $\begin{array}{r}294 \\
8.5\end{array}$ & $\begin{array}{r}16 \\
.5\end{array}$ & $\begin{array}{r}14 \\
\cdot 4\end{array}$ & & $\begin{array}{l}36 \\
1 .\end{array}$ & & & $\begin{array}{l}\text { red-red, rcd-red, } \\
\text { red-red }\end{array}$ \\
\hline ant. 1603 & Aguilar & $\begin{array}{l}\text { 53. Amigos enoja- } \\
\text { dos } \quad 3070\end{array}$ & $\begin{array}{l}168 \\
5 \cdot 5\end{array}$ & $\begin{array}{r}2785 \\
9^{0.7}\end{array}$ & $\begin{array}{r}82 \\
2.7\end{array}$ & & & & & & 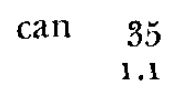 & $\begin{array}{l}\text { qui-qui, qui-qui, } \\
\text { qui-call }\end{array}$ \\
\hline ant. 1603 & Mira & $\begin{array}{l}\text { 54. Desgracias del } \\
\text { rey Alfonso } 3222\end{array}$ & $\begin{array}{r}6 \circ 9 \\
18.9\end{array}$ & $\begin{array}{r}2030 \\
63.1\end{array}$ & $\begin{array}{r}378 \\
11.6\end{array}$ & & & & & $\begin{array}{r}205 \\
6.4\end{array}$ & & $\begin{array}{l}\text { qui-qui, red-qui, } \\
\text { qui-qui }\end{array}$ \\
\hline ant. 1603 & $?$ & $\begin{array}{l}\text { 55. Fundación de } \\
\text { la Alhambra } 2660\end{array}$ & $\begin{array}{r}2468 \\
92.8\end{array}$ & $\begin{array}{r}75 \\
2.8\end{array}$ & $\begin{array}{r}48 \\
1.8\end{array}$ & & & & & $\begin{array}{r}49 \\
1.8\end{array}$ & $\begin{array}{rr}\text { can } \quad 20 \\
\quad .8\end{array}$ & $\begin{array}{l}\text { qui-red, red, } \\
\text { red-red }\end{array}$ \\
\hline ant. 1603 & $?$ & $\begin{array}{ll}\tilde{3}^{6 .} \text { Hazañas } & \text { del } \\
\text { Cid } & 24^{64}\end{array}$ & $\begin{array}{r}195^{6} \\
79 \cdot 3\end{array}$ & & $\begin{array}{r}2.00 \\
8.9\end{array}$ & $\begin{array}{r}64 \\
2.6\end{array}$ & & $\begin{array}{l}224 \\
9 \cdot 1\end{array}$ & & & & $\begin{array}{l}\text { red-rom, tcr-red, } \\
\text { oct-red }\end{array}$ \\
\hline ant. 1603 & Remón & $\begin{array}{l}\text { 57. Don Juan de } \\
\text { Austria } \quad 297^{8}\end{array}$ & $\begin{array}{r}95^{6} \\
3^{2.1}\end{array}$ & $\begin{array}{r}137^{\circ} \\
4^{6}\end{array}$ & $\begin{array}{r}3^{60} \\
12.1\end{array}$ & $\begin{array}{r}112 \\
3 \cdot 7\end{array}$ & $\begin{array}{l}42 \\
1.4\end{array}$ & $\begin{array}{r}13 \\
4\end{array}$ & & $\begin{array}{l}87 \\
3 .\end{array}$ & 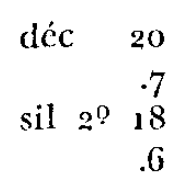 & $\begin{array}{l}\text { red-rom, red-qui, } \\
\text { sue-oct }\end{array}$ \\
\hline 1603 & Lope & $\begin{array}{l}5^{8} . \text { Arenal de Se- } \\
\text { villa } 2866\end{array}$ & $\begin{array}{l}2716 \\
94 \cdot 7\end{array}$ & & $\begin{array}{l}108 \\
3.7\end{array}$ & & $\begin{array}{l}42 \\
1.5\end{array}$ & & & & & $\begin{array}{l}\text { red-red, red-red, } \\
\text { red-red }\end{array}$ \\
\hline
\end{tabular}




\begin{tabular}{|c|c|c|c|c|c|c|c|c|c|c|c|c|}
\hline Fecha & Autor & $\begin{array}{c}\text { Titulo y } \\
\text { número de versos }\end{array}$ & red & $q u i$ & rom & oct & son & ter & lir & sue & otros & $\begin{array}{c}\text { comienzos y fina- } \\
\text { les de acto }\end{array}$ \\
\hline 1603 & Lope & $\begin{array}{l}\text { 59. Cordobés va. } \\
\text { leroso } \quad 2794\end{array}$ & $\begin{array}{r}2048 \\
73 \cdot 3\end{array}$ & $\begin{array}{l}150 \\
5 \cdot 4\end{array}$ & $\begin{array}{l}216 \\
7 \cdot 7\end{array}$ & $\begin{array}{r}272 \\
9 \cdot 7\end{array}$ & & & & $\begin{array}{r}76 \\
2 \cdot 7\end{array}$ & $\begin{array}{lr}6 \text {-s } & \text { red } \\
32 & 1.1 \%\end{array}$ & $\begin{array}{l}\text { red-qui, red-rom, } \\
\text { red-oct }\end{array}$ \\
\hline 1603 & Lope & $\begin{array}{lr}\text { 6o. Corona mere } \\
\text { cida } & 3023\end{array}$ & $\begin{array}{r}2572 \\
84.9\end{array}$ & & $\begin{array}{r}26.4 \\
8.7\end{array}$ & $\begin{array}{r}64 \\
2.1\end{array}$ & $\begin{array}{r}42 \\
1.4\end{array}$ & & & $\begin{array}{r}86 \\
2.8\end{array}$ & & $\begin{array}{l}\text { red, red-red, } \\
\text { red-rom }\end{array}$ \\
\hline ant. 1604 & Boyl & $\begin{array}{l}\text { 61. Marido asegu- } \\
\text { rado }\end{array}$ & $\begin{array}{r}3^{64} \\
9.6\end{array}$ & $\begin{array}{r}3345 \\
88.5\end{array}$ & $\begin{array}{r}5^{8} \\
1 \cdot 5\end{array}$ & & $\begin{array}{r}14 \\
.4\end{array}$ & & & & & $\begin{array}{l}\text { qui-qui, qui-qui, } \\
\text { qui-qui }\end{array}$ \\
\hline $1603-04$ & Mira & $\begin{array}{lr}\text { 62. Rueda de la } \\
\text { fortuna }\end{array}$ & $\begin{array}{r}95^{6} \\
27.8\end{array}$ & $\begin{array}{r}1465 \\
42.5\end{array}$ & $\begin{array}{r}708 \\
20.6\end{array}$ & & $\begin{array}{r}28 \\
.8\end{array}$ & & & $\begin{array}{r}246 \\
7.1\end{array}$ & déc $\begin{array}{r}40 \\
\quad 1.2\end{array}$ & $\begin{array}{l}\text { rom-qui, red-son, } \\
\text { sue-rom }\end{array}$ \\
\hline 1604 & Lope & $\begin{array}{l}\text { 63. Prueba de los } \\
\text { amigos }\end{array}$ & $\begin{array}{r}2812 \\
90.6\end{array}$ & & & $\begin{array}{r}13^{6} \\
4 \cdot 4\end{array}$ & $\begin{array}{r}28 \\
.9\end{array}$ & & & $\begin{array}{r}128 \\
4.1\end{array}$ & & $\begin{array}{l}\text { red-red, oct-red, } \\
\text { red-red }\end{array}$ \\
\hline 1604 & Lope & $\begin{array}{l}\text { 64. Desdichada } \\
\text { Estefania } \quad 26_{5} \mathbf{l}\end{array}$ & $\begin{array}{r}11 \% 6 \\
44 \cdot 4\end{array}$ & $\begin{array}{r}620 \\
23 \cdot 4\end{array}$ & $\begin{array}{r}371 \\
13.9\end{array}$ & $\begin{array}{r}272 \\
10.3\end{array}$ & $\begin{array}{l}14 \\
.5\end{array}$ & $\begin{array}{l}46 \\
1.7\end{array}$ & & $\begin{array}{r}152 \\
5.8\end{array}$ & & $\begin{array}{l}\text { qui-sue, qui-rom, } \\
\text { red-rom }\end{array}$ \\
\hline 1604 & Lope & $\begin{array}{l}65 . \text { Carlos } V \text { en } \\
\text { Francia } \quad 2800\end{array}$ & $\begin{array}{c}2020 \\
7^{2.1}\end{array}$ & $\begin{array}{r}260 \\
9 \cdot 3\end{array}$ & $\begin{array}{r}252 \\
9\end{array}$ & $\begin{array}{r}120 \\
4.3\end{array}$ & $\begin{array}{r}14 \\
.5\end{array}$ & & & $\begin{array}{r}134 \\
4.8\end{array}$ & & $\begin{array}{l}\text { red-red, red-sue, } \\
\text { qui-red }\end{array}$ \\
\hline ant. $160_{5}$ & $?$ & $\begin{array}{lc}\text { 66. Julian } & R o- \\
\text { mero } & 2910\end{array}$ & $\begin{array}{r}2284 \\
78.5\end{array}$ & $\begin{array}{r}2.50 \\
8.6\end{array}$ & $\begin{array}{r}76 \\
2.6\end{array}$ & $\begin{array}{r}160 \\
5 \cdot 5\end{array}$ & $\begin{array}{c}28 \\
1 .\end{array}$ & $\begin{array}{r}112 \\
3.8\end{array}$ & & & & $\begin{array}{l}\text { red-oct, red-red, } \\
\text { red-rom }\end{array}$ \\
\hline ant. 1605 & Aguilar & $\begin{array}{l}67 . \text { Mercader } \\
\text { amante } \quad 2963\end{array}$ & $\begin{array}{r}1664 \\
5^{6.1}\end{array}$ & $\begin{array}{l}1250 \\
42.2\end{array}$ & $\begin{array}{l}32 \\
1.1\end{array}$ & & & & & $\begin{array}{r}17 \\
.6\end{array}$ & & $\begin{array}{l}\text { qui-red, red-red, } \\
\text { qui-red }\end{array}$ \\
\hline ant. $160_{5}$ & $\begin{array}{r}\text { Salustio } \\
\text { del Poyo }\end{array}$ & $\begin{array}{l}\text { 68. Próspera for- } \\
\text { tuna }\end{array}$ & $\begin{array}{r}2932 \\
79 \cdot 7\end{array}$ & $\begin{array}{r}120 \\
3 \cdot 3\end{array}$ & $\begin{array}{r}33^{\circ} \\
9\end{array}$ & $\begin{array}{l}64 \\
1.7\end{array}$ & $\begin{array}{r}14 \\
.4\end{array}$ & & & $\begin{array}{r}217 \\
5.9\end{array}$ & & $\begin{array}{l}\text { qui-red, sue-red, } \\
\text { red-red }\end{array}$ \\
\hline
\end{tabular}




\begin{tabular}{|c|c|c|c|c|c|c|c|c|c|c|c|c|}
\hline Fecha & Autor & $\begin{array}{c}\text { Titulo y } \\
\text { número de versos }\end{array}$ & red & $q u i$ & $\mathrm{rom}$ & oct & son & ter & $\operatorname{lir}$ & sue & otros & $\begin{array}{c}\text { comienzos y fina } \\
\text { les de acto }\end{array}$ \\
\hline ant. $160_{5}$ & $\begin{array}{l}\text { Salustio } \\
\text { del Poyo }\end{array}$ & $\begin{array}{l}\text { 69. Adversa for- } \\
\text { tuna } \quad 35^{8} 7\end{array}$ & $\begin{array}{r}197^{2} \\
55\end{array}$ & $\begin{array}{r}760 \\
21.2\end{array}$ & $\begin{array}{r}740 \\
20.6\end{array}$ & & $\begin{array}{r}14 \\
.4\end{array}$ & & & $\begin{array}{c}101 \\
2.8\end{array}$ & & $\begin{array}{l}\text { rom-red, qui-red, } \\
\text { red-red }\end{array}$ \\
\hline $1604^{-06}$ & Lope & $\begin{array}{l}\text { To. Guanches de } \\
\text { Tenerife } \quad 294^{8}\end{array}$ & $\begin{array}{r}14^{84} \\
50.3\end{array}$ & $\begin{array}{l}315 \\
10.7\end{array}$ & $\begin{array}{r}698 \\
23.6\end{array}$ & $\begin{array}{r}224 \\
7.6\end{array}$ & $\begin{array}{r}28 \\
.9\end{array}$ & $\begin{array}{c}58 \\
2 .\end{array}$ & & $\begin{array}{r}141 \\
4.8\end{array}$ & & $\begin{array}{l}\text { qui-rom, red-rom, } \\
\text { red-rom }\end{array}$ \\
\hline ant. 1607 & $?$ & $\begin{array}{l}\text { 71. Caballero de } \\
\text { Olmedo } \quad 2819\end{array}$ & $\begin{array}{r}94^{\circ} \\
33.2\end{array}$ & $\begin{array}{l}1515 \\
53 \cdot 7\end{array}$ & $\begin{array}{c}28 \\
1 .\end{array}$ & $\begin{array}{r}136 \\
4.8\end{array}$ & $\begin{array}{l}70 \\
2.5\end{array}$ & & & $\begin{array}{r}120 \\
4 \cdot 3\end{array}$ & $\begin{array}{rr}\text { déc } & 10 \\
& 3\end{array}$ & $\begin{array}{l}\text { qui-son, qui-red, } \\
\text { red-red }\end{array}$ \\
\hline ant. 1608 & Aguilar & $\begin{array}{l}\text { 72. Amantes de } \\
\text { Cartago } \quad 2817\end{array}$ & $\begin{array}{r}136 \\
4.8\end{array}$ & $\begin{array}{r}2425 \\
86.1\end{array}$ & $\begin{array}{l}60 \\
2.1\end{array}$ & $\begin{array}{l}4^{\circ} \\
1.4\end{array}$ & & $\begin{array}{r}79 \\
2.8\end{array}$ & & & can $\begin{array}{r}77 \\
2 \cdot 7\end{array}$ & $\begin{array}{l}\text { qui-qui, qui-qui, } \\
\text { red-qui }\end{array}$ \\
\hline ant. 1608 & Aguilar & $\begin{array}{ll}\text { 73. Gitana } & \text { me- } \\
\text { lancólica } & 2892\end{array}$ & $\begin{array}{l}616 \\
21.3\end{array}$ & $\begin{array}{r}1790 \\
61.9\end{array}$ & $\begin{array}{l}44 \\
1.5\end{array}$ & & & $\begin{array}{r}152 \\
5 \cdot 3\end{array}$ & & $\begin{array}{c}290 \\
10 .\end{array}$ & & $\begin{array}{l}\text { qui-qui, ter-sue, } \\
\text { qui-qui }\end{array}$ \\
\hline ant. 1608 & Aguilar & $\begin{array}{lr}\text { 74. Nuera humil. } \\
\text { de } & 2988\end{array}$ & $\begin{array}{l}1116 \\
37.3\end{array}$ & $\begin{array}{r}173^{\circ} \\
57.9\end{array}$ & $\begin{array}{r}118 \\
4\end{array}$ & & & & & & $\begin{array}{rr}\text { can } \quad 24 \\
\quad .8\end{array}$ & $\begin{array}{l}\text { qui-qui, red-red, } \\
\text { qui-red }\end{array}$ \\
\hline ant. 1608 & Castro & $\begin{array}{lr}75 . & \text { Caballero bo- } \\
\text { bo } & 2847\end{array}$ & $\begin{array}{r}1944 \\
68.3\end{array}$ & $\begin{array}{r}46_{5} \\
16.3\end{array}$ & $\begin{array}{r}160 \\
5.6\end{array}$ & & & $\begin{array}{l}5^{8} \\
2 .\end{array}$ & & $\begin{array}{r}220 \\
7 \cdot 7\end{array}$ & & $\begin{array}{l}\text { red-ter, qui-rom, } \\
\text { sue-red }\end{array}$ \\
\hline 1608 & Mira? & $\begin{array}{l}76 . \text { Caballeros } \\
\text { nuevos } \quad 34^{\circ} 7\end{array}$ & $\begin{array}{r}2792 \\
81.9\end{array}$ & $\begin{array}{c}410 \\
12 .\end{array}$ & $\begin{array}{l}64 \\
1.8\end{array}$ & & $\begin{array}{r}84 \\
2.5\end{array}$ & & & $\begin{array}{l}57 \\
1.7\end{array}$ & & $\begin{array}{l}\text { oct-son, red-red, } \\
\text { red-red }\end{array}$ \\
\hline 1608 & Aguilar & $\begin{array}{lc}77 . \text { Fray } & \text { Luis } \\
\text { Bertrán } & 294^{\circ}\end{array}$ & $\begin{array}{r}75^{6} \\
25 \cdot 7\end{array}$ & $\begin{array}{r}1715 \\
5^{8.3}\end{array}$ & $\begin{array}{r}196 \\
6.7\end{array}$ & $\begin{array}{l}4^{\circ} \\
1.4\end{array}$ & & $\begin{array}{r}82 \\
2.8\end{array}$ & & $\begin{array}{r}95 \\
3 \cdot 2\end{array}$ & $\begin{array}{cc}\text { can } & 5^{6} \\
& 1.9\end{array}$ & $\begin{array}{l}\text { qui-qui, oct-qui, } \\
\text { qui-rom }\end{array}$ \\
\hline
\end{tabular}




\begin{tabular}{|c|c|c|c|c|c|c|c|c|c|c|c|c|}
\hline Fecha & Aulor & $\begin{array}{l}\text { Tilulo y } \\
\text { minero de yersos }\end{array}$ & red & $q u i$ & $r o m$ & ort & $\mathrm{son}$ & $t t^{\prime} r$ & lir & $s u c$ & otros & $\begin{array}{l}\text { comienzos y fina- } \\
\text { les de acto }\end{array}$ \\
\hline 1608 & Lope & $\begin{array}{l}78 . \text { Batalla del } \\
\text { honor }\end{array}$ & $\begin{array}{r}1828 \\
58 \cdot 5\end{array}$ & $\begin{array}{r}295 \\
9 \cdot 4\end{array}$ & $\begin{array}{r}480 \\
15 \cdot 3\end{array}$ & $\begin{array}{r}13^{6} \\
4 \cdot 3\end{array}$ & $\begin{array}{r}14 \\
\cdot 5\end{array}$ & $\begin{array}{l}40 \\
1.3\end{array}$ & $\begin{array}{c}60 \\
2 .\end{array}$ & $\begin{array}{r}199 \\
6.3\end{array}$ & déc $\begin{array}{r}72 \\
2 \cdot 3\end{array}$ & $\begin{array}{l}\text { red-rom, qui-rom, } \\
\text { qui-rom }\end{array}$ \\
\hline $1605^{-09}$ & $\begin{array}{l}\text { Valdi- } \\
\text { vielso }\end{array}$ & $\begin{array}{l}\text { 79. Angel de la } \\
\text { guarda }\end{array}$ & $\begin{array}{r}2292 \\
68.6 \\
\end{array}$ & & $\begin{array}{r}746 \\
22.3 \\
\end{array}$ & & $\begin{array}{r}14 \\
\cdot 4\end{array}$ & & & $\begin{array}{r}260 \\
7.8 \\
\end{array}$ & $\begin{array}{r}\text { déc } \quad \begin{array}{r}30 \\
9\end{array}\end{array}$ & $\begin{array}{l}\text { dec-rom, red-sue, } \\
\text { red-rom }\end{array}$ \\
\hline $1605-10$ & Castro & $\begin{array}{l}\text { 8o. Curioso im- } \\
\text { perlinenle } 3184\end{array}$ & $\begin{array}{r}2.52 \\
70.7\end{array}$ & $\begin{array}{l}540 \\
16.9\end{array}$ & $\begin{array}{r}308 \\
9 \cdot 7\end{array}$ & & $\begin{array}{l}42 \\
1.3\end{array}$ & & $\begin{array}{l}42 \\
1.3\end{array}$ & & & $\begin{array}{l}\text { red-qui, red-red, } \\
\text { qui-rom }\end{array}$ \\
\hline $1605-10$ & Castro & $\begin{array}{r}\text { 81. Don Quijote } \\
3 \mathrm{ro3}\end{array}$ & $\begin{array}{r}2120 \\
68.3\end{array}$ & $\begin{array}{r}535 \\
17.2\end{array}$ & $\begin{array}{r}44^{8} \\
14 \cdot 4\end{array}$ & & & & & & & $\begin{array}{l}\text { red-rom, qui-red, } \\
\text { qui-rom }\end{array}$ \\
\hline $1605-10$ & Mira & $\begin{array}{l}\text { 82. Esclaro del } \\
\text { demonio } \quad 3^{277}\end{array}$ & $\begin{array}{r}960 \\
29 \cdot 3\end{array}$ & $\begin{array}{c}1180 \\
3^{6}\end{array}$ & $\begin{array}{r}744 \\
22.7\end{array}$ & & $\begin{array}{r}42 \\
1 \cdot 3\end{array}$ & & & $\begin{array}{r}225 \\
6.8\end{array}$ & $\begin{array}{rr}\text { déc } & 120 \\
& 3.6 \\
\text { irr } & 6 \\
& .3 \\
\end{array}$ & $\begin{array}{l}\text { qui-red, red-red, } \\
\text { sue-rom }\end{array}$ \\
\hline $1608-10$ & Lope & $\begin{array}{ll}83 . \text { Doncella } & \text { Teo- } \\
\text { dor } & 3382\end{array}$ & $\begin{array}{r}1020 \\
30.2\end{array}$ & $\begin{array}{r}555 \\
16.4\end{array}$ & $\begin{array}{r}1010 \\
29.9\end{array}$ & $\begin{array}{r}184 \\
5 \cdot 4\end{array}$ & $\begin{array}{l}5^{6} \\
1.6\end{array}$ & $\begin{array}{r}87 \\
2.6\end{array}$ & $\begin{array}{r}54 \\
1.8\end{array}$ & $\begin{array}{r}307 \\
9\end{array}$ & $\begin{array}{lr}\text { déc } & 90 \\
& 2.7 \\
\text { sil } 2^{\circ} \quad 19 \\
& .6 \\
\end{array}$ & $\begin{array}{l}\text { red-oct, qui-rom, } \\
\text { ter-rom }\end{array}$ \\
\hline 1610 & Mira & $\begin{array}{l}\text { 84. Fénix de Sa- } \\
\text { lamanca } \quad 3370\end{array}$ & $\begin{array}{r}265^{2} \\
78.7 \\
\end{array}$ & & $\begin{array}{r}704 \\
20.9\end{array}$ & & $\begin{array}{r}14 \\
\cdot 4 \\
\end{array}$ & & & & & $\begin{array}{l}\text { red-red, red-rom, } \\
\text { red-rom }\end{array}$ \\
\hline 1610 & Lope & $\begin{array}{ll}85 . \text { Hermosa } & E s- \\
\text { ter } & 2735\end{array}$ & $\begin{array}{r}720 \\
26.3\end{array}$ & $\begin{array}{r}55^{\circ} \\
20.3\end{array}$ & $\begin{array}{r}596 \\
21.6\end{array}$ & $\begin{array}{c}216 \\
8 .\end{array}$ & $\begin{array}{r}28 \\
1 .\end{array}$ & $\begin{array}{r}34 \\
1.2\end{array}$ & $\begin{array}{r}102 \\
3 \cdot 7\end{array}$ & $\begin{array}{r}169 \\
6.2\end{array}$ & déc $\begin{array}{r}320 \\
11.7\end{array}$ & $\begin{array}{l}\text { rom-oct, sue-rom, } \\
\text { red-rom }\end{array}$ \\
\hline 1610 & Lope & $\begin{array}{rr}80 ., \text { Buena guar- } \\
\text { da. }\end{array}$ & $\begin{array}{r}165^{2} \\
57 \\
\end{array}$ & $\begin{array}{r}70 \\
2.4 \\
\end{array}$ & $\begin{array}{r}440 \\
15.2 \\
\end{array}$ & $\begin{array}{r}72 \\
2.5 \\
\end{array}$ & $\begin{array}{r}42 \\
1 \cdot 4 \\
\end{array}$ & $\begin{array}{r}34 \\
1.2 \\
\end{array}$ & $\begin{array}{r}174 \\
6 .\end{array}$ & $\begin{array}{r}347 \\
12 .\end{array}$ & $\begin{array}{lr}6 \text { can } \quad 65 \\
\\
2.2\end{array}$ & $\begin{array}{l}\text { red-rom, red-rom, } \\
\text { red-rom }\end{array}$ \\
\hline 1610 & Lope & $\begin{array}{l}8 * \text { Caballero del } \\
\text { Sacramento } 297^{6}\end{array}$ & $\begin{array}{l}1072 \\
36.1\end{array}$ & $\begin{array}{r}645 \\
21.7\end{array}$ & $\begin{array}{r}453 \\
15.1\end{array}$ & $\begin{array}{r}344 \\
4.8\end{array}$ & $\begin{array}{r}28 \\
.9\end{array}$ & $\begin{array}{r}119 \\
4 .\end{array}$ & $\begin{array}{r}192 \\
6.5\end{array}$ & $\begin{array}{r}205 \\
6.9\end{array}$ & 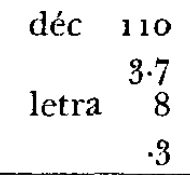 & $\begin{array}{l}\text { oct-red, qui-ter, } \\
\text { red-qui }\end{array}$ \\
\hline
\end{tabular}




\begin{tabular}{|c|c|c|c|c|c|c|c|c|c|c|c|c|c|}
\hline Fecha & Autor & $\begin{array}{c}\text { Titulo } y \\
\text { número de versos }\end{array}$ & red & $q u i$ & rom & oct & son & ter & lir & sue & \multicolumn{2}{|c|}{ otros } & $\begin{array}{c}\text { comienzos y fina- } \\
\text { les de acto }\end{array}$ \\
\hline 1610 & Lope & $\begin{array}{l}\text { 88. Cardenal de } \\
\text { Belén } 279^{\circ}\end{array}$ & $\begin{array}{r}1188 \\
42.6\end{array}$ & $\begin{array}{r}90 \\
3.2\end{array}$ & $\begin{array}{r}776 \\
27.8\end{array}$ & $\begin{array}{r}13^{6} \\
4 \cdot 9\end{array}$ & $\begin{array}{r}14 \\
\cdot 5\end{array}$ & $\begin{array}{r}138 \\
4 \cdot 9\end{array}$ & $\begin{array}{r}3^{6} \\
1.3\end{array}$ & $\begin{array}{r}229 \\
8.2\end{array}$ & $\begin{array}{l}\text { déc } \\
\text { can }\end{array}$ & $\begin{array}{r}40 \\
1.4 \\
143 \\
5.1\end{array}$ & $\begin{array}{l}\text { red-rom, red-rom, } \\
\text { red-rom }\end{array}$ \\
\hline 1610 & $\begin{array}{l}\text { Caste- } \\
\text { llano }\end{array}$ & $\begin{array}{l}\text { 89. Mientras yo } \\
\text { podo las viñas } \\
\quad 3343\end{array}$ & $\begin{array}{r}3^{6} 4 \\
10.9\end{array}$ & $\begin{array}{r}2055 \\
61.5\end{array}$ & $\begin{array}{r}674 \\
20.2\end{array}$ & $\begin{array}{r}88 \\
2.6\end{array}$ & $\begin{array}{r}14 \\
.4\end{array}$ & & $\begin{array}{r}4^{8} \\
1 \cdot 4\end{array}$ & & déc & $\begin{array}{r}100 \\
3 .\end{array}$ & $\begin{array}{l}\text { déc-qui, qui-rom, } \\
\text { lir-rom }\end{array}$ \\
\hline ant. 1611 & Sánchez & $\begin{array}{r}\text { 9o. Isla bárbara } \\
4052\end{array}$ & $\begin{array}{r}3^{868} \\
95 \cdot 5\end{array}$ & & & $\begin{array}{r}112 \\
2.7\end{array}$ & $\begin{array}{r}14 \\
.3\end{array}$ & & & $\begin{array}{r}58 \\
1.5\end{array}$ & & & $\begin{array}{l}\text { red-red, red-red, } \\
\text { red-red }\end{array}$ \\
\hline ant. 1611 & $\begin{array}{l}\text { Mejía de } \\
\text { la Cerda }\end{array}$ & $\begin{array}{l}\text { 91. Doña Inés de } \\
\text { Castro } \quad \text { sgog }\end{array}$ & $\begin{array}{r}696 \\
23 \cdot 9\end{array}$ & $\begin{array}{r}1645 \\
56.5\end{array}$ & $\begin{array}{r}226 \\
7.8\end{array}$ & $\begin{array}{r}256 \\
8.8\end{array}$ & $\begin{array}{l}42 \\
1.4\end{array}$ & $\begin{array}{r}31 \\
1.1\end{array}$ & & & call & $\begin{array}{r}13 \\
.4\end{array}$ & $\begin{array}{l}\text { qui-son, qui-qui, } \\
\text { red-red }\end{array}$ \\
\hline ant. 1611 & Grajal & $\begin{array}{ll}\text { 92. Adversa for }- \\
\text { tuna } & 2374\end{array}$ & $\begin{array}{r}1428 \\
60.2\end{array}$ & $\begin{array}{r}140 \\
5.9\end{array}$ & $\begin{array}{l}25^{\circ} \\
10.5\end{array}$ & & $\begin{array}{r}28 \\
1.2\end{array}$ & $\begin{array}{r}67 \\
2.7\end{array}$ & & $\begin{array}{l}4^{61} \\
19 \cdot 4\end{array}$ & & & $\begin{array}{l}\text { sue-red, qui-rom, } \\
\text { sue-red }\end{array}$ \\
\hline ant. 1611 & Grajal & $\begin{array}{ll}\text { 93. Próspera for } \\
\text { tuna } & 2626\end{array}$ & $\begin{array}{r}2104 \\
80.1\end{array}$ & & $\begin{array}{r}298 \\
11.3\end{array}$ & & $\begin{array}{r}14 \\
5\end{array}$ & & $\begin{array}{c}54 \\
2 .\end{array}$ & $\begin{array}{r}156 \\
5 \cdot 9\end{array}$ & & & $\begin{array}{l}\text { red-rom, sue-red, } \\
\text { red-red }\end{array}$ \\
\hline ant. 1611 & $\begin{array}{l}\text { Salustio } \\
\text { del Poyo }\end{array}$ & $\begin{array}{l}\text { 94. Alvaro de Lu. } \\
\text { na }\end{array}$ & $\begin{array}{r}1920 \\
60.4\end{array}$ & $\begin{array}{r}780 \\
24.6\end{array}$ & & & $\begin{array}{r}14 \\
.5\end{array}$ & & & $\begin{array}{r}443 \\
13 \cdot 9\end{array}$ & can & $\begin{array}{r}20 \\
.6\end{array}$ & $\begin{array}{l}\text { red-red, sue-sue, } \\
\text { sue-qui }\end{array}$ \\
\hline ant. 1611 & $\begin{array}{l}\text { Vélez de } \\
\text { Guevara }\end{array}$ & $\begin{array}{l}\text { 95. Espejo del } \\
\text { mundo }\end{array}$ & $\begin{array}{r}1300 \\
49.6\end{array}$ & $\begin{array}{r}3^{60} \\
13 \cdot 7\end{array}$ & $\begin{array}{r}700 \\
26.7\end{array}$ & & $\begin{array}{r}14 \\
.5\end{array}$ & & & $\begin{array}{r}247 \\
9 \cdot 4\end{array}$ & & & $\begin{array}{l}\text { qui-sue, qui-red, } \\
\text { qui-rom }\end{array}$ \\
\hline ant. 1611 & $\begin{array}{l}\text { Vélez de } \\
\text { Guevara }\end{array}$ & $\begin{array}{l}9^{6 .} \text { Hijos de la } \\
\text { Barbuda } \quad 2763\end{array}$ & $\begin{array}{r}1184 \\
42.8\end{array}$ & $\begin{array}{r}310 \\
11.2\end{array}$ & $\begin{array}{r}794 \\
28.7\end{array}$ & $\begin{array}{c}5^{6} \\
2 .\end{array}$ & 14 & $\begin{array}{l}161 \\
5.8\end{array}$ & & $\begin{array}{r}244 \\
8.8\end{array}$ & & & $\begin{array}{l}\text { ter-rom, soll-red, } \\
\text { red-rom }\end{array}$ \\
\hline
\end{tabular}




\section{NOTAS AL CUADRO A}

1. Los celos de Rodamonte (Chron., pp. 20, 140). Esta comedia y la siguiente se hallaban en 1588 en poder de Gaspar de Porres. Cf. CelesTINo Lóplz Martínez, Teatros y comediantes sevillanos del siglo xvi, Sevilla, 1940, p. 31; BC, 5 (1953), 30-31; BHi, 57 (1955), $5^{6 .}$

2. Las ferias de Madrid (Chron., pp. 21, 143-144). Copia ms. en la Bibl. de Palacio, fechada en Granada, 17 de enero de 1589. Cif. Bruerton en $\mathrm{BH}, 57$ (1955), 56-79.

3. El principe inocente (Gálvez). Madrid, 2 de junio de 1590 . Inédita. Debo las cifras a la gentileza de don Agustín G. de Amezúa.-Pasajes: 10 red, 1 qui ( 85 vs. de 1,55 de 5 ), 2 oct, 1 son $B, 4$ ter, 3 sue (sin ningún pareado).-Vs. españoles: $75.5 \%$.-Pasajes más largos: red 272, oct 40, ter 241 (final del acto III), sue 65.-La comedia es insólitamente corta para la ćpoca. Quizá el copista haya omitido los versos suprimidos por los actores, como hizo en El marqués de Mantua (véase infra, núm. 15).

4. Carlos el perseguido (Gálvez). Toledo, 2 de noviembre de $159^{\circ}$. Cilron., pp. 17, 134.

5. Juan de Quirós y Toledo, La famosa toledana. Copia ms. fechada en 1591, ed. por Rachel Alcock en $R H i, 41$ (1917), 336-562. La fecha puesta en una copia ms. no da ciertamente una base firme para averiguar la de composición; pero la versificación no se parece en nada a la de las comedias anteriores a 1587 -Pasajes: 4 red, 3 sue (diál., m. l., m. ad. y diál.), 1 oct. Total de pasajes: $8(1,6,1)$.-Vs. españoles: $96.7 \%$-Pasajes más largos: red 1064 (acto III), sue 45 .

6. Francisco Agustín Tárrega, El prado de Valencia (Doce com.; $B A A E E$, t. 43). Según Mérimée (p. 519), la comedia se escribió en ${ }_{15} 89$ a raíz de la epidemia, y la relación de un torneo celebrado en septiembre de 1590 se añadió a la comedia a fines de este año. Juliá (t. 1, p. lxxvi) es de la misma opinión. Sin embargo, no parece muy necesario hacer tales suposiciones. La severa epidemia que asoló a Valencia y Cataluña en 1588-89 no caería tan pronto en el olvido, y en la comedia española son muy comunes los relatos de sucesos sin relación estricta con la trama. En cambio, la larga relación del torneo sí debe haberse hecho poco después, porque de lo contrario no tendría interés para el público, ni siquiera en Valencia. De ahí el ligero cambio de fecha que sugiero. -Pasajes: 8 red, 3 qui, 1 rom, 2 oct (d. interr., m. n.), 1 son B (m. ad.), 2 sue (sin pareados) (eco, diál.).-Vs. españoles: 90.3\%.-Pasajes más largos: red $123^{6}$ (comienzo del acto I), qui 495, oct 240 , sue 41.

7. Las burlas y enredos de Benito (Chron., p. 261).

8. El caballero del milagro (Gálvez). Alba, noviembre-diciembre de 1595. Chron., pp. 20, 139-140.

9-13. El favor agradecido (Gálvez), El maestro de danzar, El leal criado, San Segundo de Avila, Laura perseguida (Chron., pp. 14, 32).

14. El hijo venturoso (Chron., pp. 14, 33).

15.-El marqués de Mantua (Gálvez). Madrid, 10 de enero de 1596. El copista omitió los pasajes suprimidos seguramente por los actores, y 
luego los copió en su totalidad, al final de la comedia. Chron., pp. 22, $14^{8 .}$

16. La francesilla (Gálvez). Madrid, 6 de abril de 1596. Chron., pp. 16,34 .

17. El remedio en la desdicha (Gálvez). Madrid, 16 de octubre de 1596. Chron., pp. 17, 135-136.

18. La bella mal maridada (Gálvez). Madrid, 17 de diciembre de 1596. Chron., pp. 15, 127.

19. Los comendadores de Córdoba. En cuanto a la fecha, cf. Chron., pp. 15, 128-129; "Add", p. 57 (núm. 19); María Goyri de Menéndez PIdal en NRFH, 4 (1950), $367-37$ o, y S. G. Morley y C. Bruerton, ibid., 6 (1952), 62-64.

20. El amor desatinado (Gálvez). Toledo, 4 de junio de 1597. Debo las cifras al señor Amezúa.-Pasajes: 9 red, 2 qui (19o vs. de 1, 120 de 2, 220 de 5), 3 rom, 3 son B, 3 oct, 1 lir aBaBcC, 1 lir AabBcc, 5 sue (sin pareados), 1 can abCabCcdeeDeE. Total de pasajes: 28 (8, 7,13$)$.Vs. españoles: $72.8 \%$.-Pasajes más largos: red 312, qui 350 , rom 80 , oct 88 , lir 144 , sue 117 .

21. La imperial de Otón (Gálvez). Madrid, 28 de septiembre de 1597. Chron., pp. 17, 133-134.

22. Viuda, casada y doncella (Gálvez). Madrid, 22 de octubre de 1597. Chron., p. 248.

23. Los torneos de Aragón (Gálvez). Madrid, 14 de noviembre de 1597. Chron., pp. 15, 126-127.

24. Guillén de Castro, El amor constante (Doce com.). E. Julrá Mar. TíNEz, Obras de G. de C., t. 1, p. 11, cree escrita la comedia hacia 1593. Cf. C. Bruerton en $H R, 12$ (1944), 94. 'J. M. Roca Franquesa, RFE, 28 (1944), 393, la fecha en 1597-99, y luego, p. 394, en 1598-99.

25. El desengaño dichoso (Primera parte de Castro, 1618). Cf. Juliá Martínez, Obras de G. de G., t. 1, p. Ixxxiii, y C. Bruerton, $H R, 12$ (1944), 94-95.

26. Los cautivos de Argel (Chron., p. 263).

27. El tirano castigado (Gálvez). Madrid, 17 de julio de 1599. Chron., pp. 23,154 .

28. El blasón de los Chaves de Villalta. Dos copias mss., la de Sanz de Pliegos y la de Gálvez; ésta tiene 139 vs. más que aquélla. Tal vez. Sanz omitió los versos tachados. Chron., pp. 16, 34 .

29. El amigo por fuerza (Gálvez). Madrid, 14 de octubre de 1599. Chron., pp. 18, 36 .

3o. La varona castellana (Gálvez). Madrid, 2 de noviembre de 1599. Chron., pp. $23,155$.

31. Las pobrezas de Reinaldos (Chron., pp. 16, 34).

32. La sangre leal de los montañeses de Navarra. Copia ms., B. N. M., fechada a 27 de octubre de 1600 (Doce com.; Julí).-Pasajes: 3 qui, 1 rom (comienzo de la obra). Total de pasajes: 4 (2, 1, 1).-Vs. españoles: $100 \%$.-Pasaje más largo: qui 1195 (acto II).

33. Miguel Beneyto, El hijo obediente (Doce com.; Juliá). Beneyto murió en 1600.-Pasajes: 4 red, 7 qui, 2 rom, 1 son $\mathrm{B}, 1$ ter (m.ad. más 
un verso).-Vs. españoles: 93.9\%.-Pasajes más largos: red 212, qui 815 (comienzo del acto III), rom 72 .

34. Los embustes de Celauro (Gálvez). Madrid, 25 de enero de 1600. Ed. J. de Entrambasaguas, 1942. Chron., pp. 18, $3^{6 .}$

35. La contienda de Garcia de Paredes y el valiente Juan de Heredia (Sanz de Pliegos, Gálvez). Madrid, 15 de febrero de 1600. Chron., pp. 16 , 35 (es errónea, en la p. 35, la afirmación de que la comedia se publicó en la Parte $\mathrm{XI}$ ).

36. El ingrato arrepentido (Gálvez). 2 de abril-2 de octubre de 1600. Chron., pp. 21, 146.

37. Los Benavides (Gálvez). Madrid, 15 de junio de 160o. Chron., pp. 17,134 .

38. Luis Vélez de Guevara, El prodigioso principe Transilvano (Chron., p. 331). Cf. RPh, 6 (1952-53), 249, 253.

39. La fortuna adversa del infante don Fernando de Portugal. Tomo $13^{2}$ (Osuna), ed. A. E. Sloman, Oxford, 1950. Sloman (pp. 103-115) se inclina a atribuir esta obra a Tárrega, y le asigna la fecha 1595-98. Sus argumentos son buenos, pero en contra de la atribución está el porcentaje de romance. El mayor número de versos de romance en las obras conocidas de Tárrega está en $E l$ cerco de Pavía (infra, núm. 4o): 3 pasajes, 248 vs., $6.1 \%$. Ninguna de sus comedias auténticas termina en romance. En cambio, no es imposible que Tárrega compusiera esta obra en los últimos años de su vida. En cuanto al terminus ad quem que sugiere Sloman, véase lo que se dice adelante acerca de los valencianos. Sobre la versificación, cf. Sloman, pp. $105^{-106 .}$

40. El cerco de Pavia y prisión del rey de Francia (Norte).-Pasajes: 7 red, 2 qui, 1 déc, 3 rom (ms. n, m. n. interr.). Total de pasajes: $13(3,5,5)$.-Vs. españoles: $100 \%$.-Pasajes más largos: red 1024, qui 275 , rom 96 .-Única obra de Tárrega en que hay décimas, lo cual parece indicar que su fecha es 1596-1601.

41. Las suertes trocadas y torneo venturoso (Doce com.).-Pasajes: 9 red, 2 rom, 2 son $\mathrm{B}, 5$ oct (diál., m. 1., m. ad.). Total de pasajes: 18 $(9,2,7)$.-Vs. españoles: $95.6 \%$.-Pasajes más largos: red 1388 (final del acto II), rom 96 , oct $5^{6}$.

42. La duquesa constante (Norte).-Pasajes: 7 red, 11 qui, 3 rom, 1 son $\mathrm{B}, 1$ ter, 2 oct, 3 sue sin ningún pareado (diál., m. n. interr., diál.). Total de pasajes: $28(4,8,16)$.-Vs. españoles: $87.9 \%$.-Pasajes más largos: red 248 , qui 310 , rom 32 , oct 64 , sue 75 .

43. La perseguida Amaltea (Doce com.).-Pasajes: 5 red, 6 qui, 1 son CDEDCE. Total de pasajes: $12(3,3,6) .-$ Vs. españoles: $99.5 \% .-$ Pasajes más largos: red 368 , qui 415 .

44. La fundación de la orden de Nuestra Señora de la Merced (Norte).-Pasajes: 1 red, 6 qui, 2 rom, 1 sue sin ningún pareado $(\mathrm{m}$. $\mathrm{n}$. y diál.). Total de pasajes: $10(6,1,3)$--Vs. españoles: $98 \%$.-Pasajes más largos: qui 1030 (acto II), rom 80.

45. La enemiga favorable (Flor). Mencionada en el Quijote, I, 48. Puede haberse escrito hacia 1590-95.-Pasajes: 4 qui, 2 oct (diál., m. n. interr.). Total de pasajes: $6(4,1,1) .-$ Vs. españoles: $97.9 \%$-Pasajes más largos: qui 1305 (acto III), oct 64 . 
46. El cerco de Rodas (Doce com.).-Pasajes: 5 qui, 2 rom. Total de pasajes: $7(3,1,3)$-Vs. españoles: $100 \%$-Pasajes más largos: qui 890 (acto II), rom 96 .

47. El esposo fingido (Doce com.).-Pasajes: 5 red, 6 qui, 1 rom, 1 son B. Total de pasajes: $13(4,4,5) .-V s$. españoles: $99.5 \%$-Pasajes más largos: red 264, qui 535 (comienzo del acto III).

48. La reina penitente. Copia ms., B. N. M. Cf. G. E. WAdE en $B C$, 7 (1955), 3-8. A la amabilidad del profesor Wade debo las cifras de esta comedia.-Pasajes: 10 red, 1 qui, 2 rom, 1 oct, 1 lir aBaBcC, 4 sue. Total de pasajes: $19(6,7,6)$.-Vs. españoles: $89.9 \%$-Pasajes más largos: red 392 , rom 6 o, sue 75 .

49. El conde Alarcos (Parte I de Castro, 1618). Cf. Brulrton, HR, 12 (1944), 93, 95-96.

50. El cuerdo loco y veneno saludable (Chron., pp. 17, 35).

51. El principe despeñado (Chron., pp. 17, 36).

52. Gaspar de Mesa, El Bruto ateniense. Copia ms., B. N. M. Cf. SAN RomÁN, p. Ixxxi y nota 1, p. 1 y documento 97.-Pasajes: 7 red, 1 qui, 3 rom, 1 oct, 1 son $\mathrm{B}, 2$ lir aBaBcC (una en italiano, la otra m. 1.).-Vs. españoles: $98 \%$-Pasajes más largos: red 652 , rom 118 , lir 24.

53. Los amigos enojados y verdadera amistad (Seis com.; Chron., p. 256). Cf. Bruerton en HR, 12 (1944), 223-234.

54. Las desgracias del rey don Alfonso el Casto (Flor). Vendida por Alonso de Heredia a Pedro de Valdés el 21 de enero de 1609 (SAN RoMÁN, doc. 132).-Pasajes: 5 red, 11 qui, 9 rom (m. n., ms. n. y diál.), 3 sue (con $1.9 \%$ de pareados). Total de pasajes: $22(5,7,10)$.-Vs. españoles: 93.6\%.-Pasajes más largos: red 18o, qui 495, rom ${ }_{15}$ o, sue 112.

55. La fundación de la Alhambra (Seis com.). Copia ms. en la B. N. M. Chron., p. 288.

56. Las hazañas del Cid y su muerte, con la toma de Valencia (Seis com.). Chron., p. 291.

57. Don Juan de Austria en Flandes (Chron., 276-277).

58-6o. El arenal de Sevilla, El cordobés valeroso Pedro Carbonero, La corona merecida (Gálvez) (Chron., pp. 19, 38).

61. Carlos Boyl, El marido asegurado (Norte; BAAEE, t. 43). Parece que se representó por vez primera en 1603 (MÉrimée, p. 533)--Pasajes: 2 red, 7 qui, 1 son $A$, 1 rom (m. ad. interr.). Total de pasajes: 11 (5, 3, 3).-Vs. españoles: 99.6\%.-Pasajes más largos: red 200, qui 790.

62. La rueda de la fortuna (BAAEE, 43). Representada en Toledo en el verano de 1604 (Rennfrt-Castro, Vida de Lope, p. 161).-Pasajes: 9 red, 10 qui ( 1 y 5 ; algunas forman copla real), 2 son $\mathrm{B}, 3$ déc (ms. 1.), 5 rom (ms. ad., m. n., m. ad. y diál.), 3 sue (diál., m. ad. y diál., m. ad.). Total de pasajes: $32(8,15,9)$.-Vs. españoles: $92.1 \%$.Pasajes más largos: red 280, qui 425, déc 20 (3), rom 206, sue 210 (comienzo del acto III).

63-65. La prueba de los amigos, La desdichada Estefania, Carlos V en Francia (Chron., pp. 24, 38). Sobre Carlos V (Gálvez), cf. Amezúa, pp. 98-117, y "Add", p. 69.

66. Julián Romero (Chron., p. 297).

67. El mercader amante (Norte). Mencionado en el Quijote, I, $4^{8} \mathrm{y}$, 
por lo mismo, anterior a 1605 . Puede ser muy anterior. Las otras obras mencionadas ahí por Cervantes son su propia Numancia (penúlt. décacla del siglo xvi), La ingratitud vengada de Lope (fechada, por su versificación, en 1588-95), y La enemiga favorable de Tárrega (supra, núm. 45).-Pasajes: 6 red, 6 qui, 1 rom, 1 sue.-Pasajes más largos: red 512, qui 340 (comienzo del acto I).

68. Damián Salustio del Poyo, La próspera fortuna del famoso Ruy López de Ávalos el Bueno (Parte III de Lope, 1612). Vendida, junto con la siguiente (núm. 69), el 26 de abril de 1605 (SAN Román, doc. 193). Salustio del Poyo nació en $15^{80}$ y es mencionado en El viaje entretenido (160g), ed. Cañete, p. 148. La fecha de las comedias parece ser 1600-o.1.-Pasajes: 8 red, 2 qui (tipo 1), 4 rom (m. ad. y diál., ms. n. y diál.), 1 oct, 2 sue (sin pareados), 1 son $B$. Total de pasajes: 18 (5, 6, 7).-Vs. españoles: 93.7\%.-Pasajes más largos: red 920, qui 95, rom 118 , sue 190 .

69. La adversa fortuna del muy noble caballero Ruy López de Ávalos el Bueno (Parte III de Lope, 1612; BAAEE, 43). Cf. núm. anterior.-Pasajes: 11 red, 4 qui, 7 rom (ms. n. y diál., ms. ad., m. n. interr., m. n.), 1 son $B$, 1 sue (sin pareados).-Vs. españoles: 96.8\%.-Pasajes más largos: red 316, qui 290 , rom 192 .

7o. Los guanches de Tenerife y conquista de Canarias (Chron., pp. 24, 39).

71. El caballero de Olmedo. Copia ms. B. N. M., fechada en 1606, con licencias de 1607 . Ed. E. Juliá Martínez, Madrid, 1944.-Pasajes: 7 red, 8 qui $(1,5$, casi siempre en copla real), 1 déc, 1 rom, 2 oct (m. $n$. interr., m. n. y diál.), 5 son $\mathrm{B}$ (ms. ad.), 1 sue (con $1.7 \%$ de pareados). Total de pasajes: $21(5,5,11)$-Vs. españoles: $88.3 \%$--Pasajes más largos: red $39^{2}$, qui $39^{\circ}$, oct 88 .

72. Los amantes de Cartago (Doce com.).-Pasajes: 1 red, 7 qui, 1 rom, 1 oct, 1 ter (m. ad. y diál.), 2 can aBaBbCC (m. l.).-Vs. españoles: $93 \%$.-Pasajes más largos: qui 615 , can 42.-El Fray Luis Bertrán de Aguilar (infra, núm. 77 ) tiene $58 \%$ de quintillas, y su Juan de Ribera $\left(1611^{-15}\right)$ sólo $21.9 \%$, o sea que, al igual que otros autores, Aguilar parece haber ido rebajando con el tiempo el número de esta forma estrófica. Parece improbable que un $86 \%$ de quintillas sea muy posterior a 1600 . El número de vs. de romance es apenas inferior al de $L o s$ amigos enojados (supra, núm. 53). La comedia puede fecharse hipotéticamente: ca. 1600.

73. La gitana melancólica (Doce com.).-Pasajes: 3 red, 10 qui, 1 rom, 2 ter (m. ad. y diál.), 5 sue sin pareados (m. n. y diál., diál.). Total de pasajes: $21(8,7,6) .-$ Vs. españoles: $84.7 \%$.-Pasajes más largos: red 276 , qui 33o, ter 79 , sue 86.-Mérimée (p. 538) cree probable que ésta sea la más antigua de las comedias de Aguilar, porque reúne "un grand nombre de rhythmes mais n'admet pas de vers quebrado". Puede ser así, pero no es seguro. La comedia data con certeza de 1590-1607; probablemente no se escribió después de 1600.

74. La nuera humilde (Doce com.).-Pasajes: 5 red, 5 qui, 2 rom, 1 can abCabCDD (m. 1.).-Vs. españoles: 99.2\%.-Pasajes más largos: red 292, qui 540, rom 72.-Según Mérimée (p. 538), pertenece a la pri- 
mera época de Aguilar (antes de 160o), a pesar de contener versos "quebrados" (la canción) que, según él, sólo aparecen después de 1600; y la pone inmediatamente antes de El mercader amante, que sólo tiene $1.1 \%$ de romance y ninguna canción. El porcentaje de romance de La nuera puede compararse con el $6.7 \%$ de Fray Luis Bertrán. Fuera de La nuera, las únicas comedias que tienen dos pasajes de romance son Fray Luis Bertrán (1608), La suerte sin esperanza (1608?-15) y Juan de Ribera (1611-15). La pieza puede ser bastante tardía, de 1606-07. Lo indudable es que pertenece al período $1600-07$.

75. El caballero bobo (Doce com.). Cf. Bruerton en $H R, 12$ (1944), pp. 93,96 .

76. Los caballeros nuevos y carboneros de Tracia. Copia ms., B. N. M., fechada en Valladolid, 7 de marzo de 1608. Cf. E. Cotarelo, Mira de Amescua y su teatro, Madrid, 1931, pp. 57-59. Cotarelo no está seguro de que sea de Mira, y, en caso de serlo, la cree de sus primeras obras. Le sirve de apoyo el hecho de que hay 19 casos de rimas ilícitas en las quintillas, y 22 casos en las redondillas. Doy las gracias al Prof. Ramon Rozzell y a Mr. Frank Platt, de la Ohio State University, por haberme facilitado la copia fotostática que perteneció al Prof. Anibal.--Pasajes: 8 red, 2 qui (en coplas reales), 1 oct (diál. y m. n.), 3 pares de sonetos B, 1 sue (sin pareados). Total de pasajes: $15(7,5,3)$.-Vs. españoles: $93.9 \%$. -Pasajes más largos: red 924, qui 220.

77. La vida y muerte del santo fray Luis Bertrán (Fiesta; Juliá). Representada el $1^{\circ}$ de septiembre de 1608 (Mérimée, p. 520).-Pasajes: 3 red, 9 qui (tipo 1), 3 rom (ms. n., m. ad.), 1 oct, 2 sue sin pareados (diál., m. n.), 1 ter (sermón), 1 can aBaBbCC (m. l.). Total de pasajes: $20(3,10,7)$.-Vs. españoles: 90.7\%.-Pasajes más largos: red 348, qui $5^{6} 5$, rom 96 , sue 86 .

78. La batalla del honor (Gálvez). Chron., pp. 25, 40.

79. José de Valdivie[l]so, El ángel de la guarda. Copia ms., B. N. M. Representada el 11 de septiembre de 1609 (SAN Román, p. Ixxix y doc. 276). Hacia el final del acto II, 5 líneas antes de acabar el fol. $37 \mathrm{v}^{\prime \prime}$ : “...como el bravo don Quijote". Así, pues, la comedia se escribió en 1605-09, tal vez en 1609.-Pasajes: 11 red, 1 déc, 6 rom (diál., m. 1 . y diál., ms. ad. y diál., m. $\mathrm{n}$. ), 1 son $\mathrm{B}, 5$ sue (con $0.8 \%$ de pareados) (diál., m. 1.). Total de pasajes: $24(7,8,9)$.-Vs. españoles: $91.8 \%$.-Pasajes más largos: red $5^{16}$, rom 180 , sue $7^{6}$.

8o. El curioso impertinente. Cf. Bruerton, $H R, 12$ (1944), 93, 96, 97.

81. Don Quijote de la Mancha. Cf. Bruerton, ibid.

82. El esclavo del demonio (Parte III de Lope, 1612, aprobación de 1611). Ed. M. A. Buchanan, Baltimore, 1905, y A. Valbuena Prat, Zaragoza, 1942. Valbuena le asigna la fecha 1605-10. Como Mira marchó a Italia en 1610 , el terminus ad quem puede ser 1609 . Representado en Lima durante la octava del Corpus de 1612 (G. Lohmann Villena, El arte dramático en Lima, Lima, 1941, p. 86).-Pasajes: 8 red, 6 qui (1 y 5), 2 déc (ms. 1. y diál.), 5 rom (ms. ad. y diál., ms. n. y diál.), 3 son $\mathrm{P}$; y 1 son $\mathrm{C}$ (ms. 1.), 1 son A, 6 sue sin pareados (m. l., diál.), Total de pasajes: $30 \quad(8,13,9)$.-Vs. españoles: $91.3 \%$.-Pasajes más largos: red 164 , qui 275 , déc 70 , rom 172 , sue 57 . 
83. La doncella Teodor (Chron., p. 19o; "Add", p. 59).

84. La fénix de Salamanca (BAAEE, 43). E. Cotarelo, Mira de Amescua, p. 20 y nota 1 , dice que es de comienzos de 1610.-Pasajes: 5 red, 3 rom (m. n. interr., ms. ad. y diál., diál.), 1 son A. Total de pasajes: $9(3,4,2)$.-Vs. españoles: $99.6 \%$.-Pasajes más largos: red 840 , rom 264 .

85-87. La hermosa Ester, La buena guarda, El caballero del sacramento (Chron., pp. 25, 40).

88. El cardenal de Belén (Chron., pp. 26, 40).

89. Agustín Castellano, Mientras yo podo las viñas. Ms., B. N. M., fechado en 1610. Cf. SAN Román, pp. ci-cvii, y dos láminas (San Román escribe "Castellanos", pero en el ms. se lee "Castellano").-Pasajes: 3 red, 7 qui ( 1760 vs. de 1,20 de 3,275 de 5), 1 déc (ms. ad.), 5 rom (diál. y ms. ad., diál.), 1 oct, 1 son $\mathrm{B}$, 1 lir aBaBcC (m. l.). Total de pasajes: $19(8,6,5)$.-Vs. españoles: $95.6 \%$.-Pasajes más largos: red 180 , qui 665 , rom $212 .-\mathrm{El} 20.2 \%$ de romance y la conclusión de dos actos con este metro son cosas normales para 1610 , pero sorprende el $61.5 \%$ de quintillas. Como Castellano no sabía escribir, es probable que siguiera apegado a costumbres más viejas. Los actores suprimieron 146 vs. en el acto I, 154 en el II y 98 en el III (total, 398 ), dejando 2945 vs. para la representación.

9o. Miguel Sánchez, La isla bárbara. Copia ms., B. N. M., con licencia de 1611 . Ed. H. A. Rennert, Boston, 1896. Otra copia ms. lleva fecha de ${ }_{15}^{89}$ (cf. Rennert, pp. xiv-xv).-Pasajes: 4 red, 2 oct (diál., m. ad., m. l.), l son B (m. ad.), l sue sin pareados (m. n.). Total de pasajes: $10(4,3,3)$--Vs. españoles: 95.5\%.-Pasajes más largos: red 1984 , oct 96.-La versificación es de tipo primitivo; la fecha de la comedia bien puede ser $15^{89}$.

91. Luis Mejía de la Cerda, Doña Inés de Castro (Parte III de Lope. 1612).-Pasajes: 7 red, 7 qui (tipo 1, algunas del 5 , y de vez en cuando del 2 y del 3), 4 rom (carta, ms. n., ms. ad., diál.), 3 oct (diál., ms. ad. y diál., ms. ad.), 3 son B, 1 ter, 1 can abCabCcddeDFF (m. l.). Total de pasajes: $25(6,10,9)$.-Vs. españoles: $88.2 \%$.-Pasajes más largos: red 268 (fin del acto III), qui 58o, rom 68, oct 88 (2).-Tres de las comedias del autor se escribieron antes de 1603 (SAN ROMÁn, doc. 132); a ellas se puede añadir la presente, pues el fuerte porcentaje de quintillas y el escaso de romance, sin ningún pasaje largo, y además los finales de acto, invitan a suponerlo. Fecha: 1600 ? -1605 ?

92. Juan Grajal, La adversa fortuna del caballero del Espiritu Santo (Parte III de Lope, 1612).-Pasajes: 7 red, 3 qui (tipo 1), 3 rom (ms. ad., diál., m. n., diál.), 1 son A, 1 son $B$ (oración, m. I.), 1 ter, 4 sue (sin pareados). Total de pasajes: $20(4,7,9)$.-Vs. españoles: $76.6 \%$. Pasajes más largos: red 468 , qui 110 , rom 142 , sue 320 .-Es casi seguro que hay supresiones en esta comedia. Una escena de 47 sueltos en el acto I comienza demasiado abruptamente; otra de 15 sueltos en el III es brevísima, y un pasaje del III, también de sueltos, sólo tiene 25 versos. Además, teniendo en cuenta la comedia siguiente, se puede decir que en su forma original La adversa fortuna de Grajal tenía más redondillas. El porcentaje de sueltos, tan elevado, se explica simplemente por la bre- 
vedad del texto. Cf. los sueltos en los núms. 11, 13 y 94. La fecha cs probablemente 1600 ?-1605?

93. Juan Grajal, La próspera fortuna del caballero del Espiritu Santo (Parte III de Lope, 1612).-Pasajes: 8 red, 2 rom, 1 son $\mathrm{B}$, 1 lir aBaBcC, 3 sue (sin pareados). Total de pasajes: $15(2,8,5)$.-Vs. españoles: 91.4\%.-Pasajes más largos: red 878 (comienzo del acto I), rom 168, sue 96.-Los actos contienen, respectivamente, 1006, 924 y 696 vs. El final parece demasiado rápido; tal vez se suprimió algo en el acto III. Por su versificación, esta comedia parece escrita hacia la misma época que el núm. $9^{2}$.

94. La privanza y caida de don Alvaro de Luna (Parte III de Lope, 1612).-Pasajes: 8 red, 7 qui (195 vs. de 1,380 de 3,180 de 5,15 de 2 y 10 de 7 ), 1 son $B, 4$ sue (con $0.4 \%$ de pareados) (ms. ad., diál.), 1 lir aBabB (m. ad.). Total de pasajes: 21 (9, 6, 12).-Vs. españoles: 85\%.Pasajes más largos: red 548, qui $35^{\circ}$, sue 104.-Los únicos versos de romance se encuentran en dos pasajes cantados. Esto contrasta fuertemente con el $20.6 \%$ del núm. 69 , y sugiere una fecha no posterior a la de esta comedia. Salustio del Poyo nació el 16 de enero de 1580 (BLANCA DE Los Ríos, ed. Obras compl. de Tirso, t. 1, p. 1855), de modo que el Don Alvaro de Luna data, con toda probabilidad, de $1600-05$.

95. El espejo del mundo (Parte III de Lope, 1612). Fecha: 16o6?1610. Cf. Bruerton en RPh, 6 (1952-53), 248-253.

96. Los hijos de la Barbuda (Parte III de Lope). Fecha: 1608?-1610. Cf. Bruerton, ibid.

Cuando se comparan las seis primeras comedias del Cuadro A con las comedias anteriores a $1587^{\circ}$, parece extraordinario, a primera vista, que en menos de una década haya ocurrido semejante cambio en la versificación. Nuestras seis primeras comedias son evidentemente mucho más largas, y el porcentaje de versos italianos se ha reducido en forma muy notable.

En general, los primeros dramaturgos comenzaron por imitar en sus obras los paradigmas clásicos. Las tragedias griegas contienen entre $105^{\circ}$ y 1780 versos, aproximadamente. Así, encontramos que ocho de las catorce obras de Juan de la Cueva tienen entre 1284 y 1870 versos; otras seis de las 23 enumeradas por Morley tienen menos de 2014. El número de versos de Los amantes de Rey de Artieda es 1595 , y 1808 el de la Comedia Jacobina de Damián de Vegas.

Sin embargo, no todas las comedias eran tan cortas. Siete de esas mismas 23 contienen de 2300 a $275^{\circ}$ versos. Por otra parte, la longitud no constituye una prueba para la cronología. En 1579, La muerte del rey don Sancho de Cueva tiene 1284 versos, con un $44 \%$ de italianos; y en el mismo año escribió La constancia de Arcelina, con 2317 versos (italianos, 43\%). También hay que tener en cuenta

5 Morley, art. cit. del HMP, pp. 530-531, da las cifras de 23 de estas comedias, como también de La isla bárbara de Miguel Sánchez (cf. supra, Cuadro A, núm. 9o). 
que el número de versos no indica correctamente la duración de la obra: los hendecasílabos, versos de más empaque, se recitarían más despacio que los familiares octosílabos, y además, lo equivalente a 2182 hendecasílabos son 3000 octosílabos. Así, los 2318 versos (de 7 , 8 y 11 sílabas) de La gran Semiramis de Virués equivalen a 2980 octosílabos, y los $275^{\circ}$ versos de El viejo enamorado ( $15^{80}$ ) de Cueva, a 3281 octosílabos, que es más o menos el promedio habitual una década más tarde ${ }^{6}$.

Por otra parte, no en todas las comedias de $1579-1585$ hay predominio de versos italianos. Siete de las de Cueva tienen de 8.3\% a $43 \%$, y todas ellas son del año 1579 . Tres comedias de contemporáneos suyos tienen entre $35 \%$ y $48.6 \%$. El tutor de Cueva, con $8.3 \%$ de versos italianos, y El degollado, del mismo autor, con $19.7 \%$, son presagios de lo que ocurrirá después de $15^{88}$. Sólo en los comienzos y finales de acto difieren de las comedias posteriores: $E l$ lutor, can-red, ter-red, oct-red, oct-red; El degollado, oct-red, oct-red, can-red, ter-red. El Atila furioso de Virués tiene incluso comienzos y finales muy parecidos a algunos que de vez en cuando se encuentran años después: qui-red, qui-oct, oct-oct (cf. Cuadro A, núm. 12; Chron., "Table I", núm. 83). Sin embargo, si algunas obras de 157985 tienen una versificación comparable a la de una década más tarde, son muy pocas las de $15^{87}$ y años subsiguientes $-y$ éstas son siempre de Lope- que parecen reflejar los esquemas predominantes en el período anterior (cf. Cuadro A, núm. 1; Chron., "Table I", núms. 12,90 ).

Las diferencias entre las comedias anteriores a 1587 y las de Lope y sus contemporáneos escritas después de este año se pueden ver claramente en el Cuadro $B$, que da el número de comedias que contienen cada metro, y el porcentaje más elevado del metro en cuestión:

\section{CUADRO B}

26 comedias anteriores a $15^{8} 7^{7}$

${ }_{183}$ comedias de $1587-1610$ ( 131 de Lope, 52 de otros)

$\begin{array}{rrrrr}22 & 91.7 \% & \text { red } & 180 & 97.9 \% \\ 7 & 51.7 \% & \text { qui } & 164 & 97.9 \% \\ & & \text { déc } & 29 & 11.7 \%\end{array}$

${ }^{\text {B }} \mathrm{Si}$ los versos italianos de las dos primeras comedias del Cuadro A se reducen a octosílabos, los totales vienen a ser 3693 y $35^{10}$, respectivamente.

' Son las 23 que da Morley (omitiendo La isla barbara), y además Los hechos de Garcilaso de Lope (Chron., "Table I", núm. 1), Los amantes de Rey de Artieda y la Comedia Jacobina de Damián de Vegas. Esta última obra se publicó en $159^{\circ}$, pero su versificación parece del primer periodo de las comedias de tres actos $(1589$ ? -84 ? $)$. Contiene 1908 vs., en esta proporción: red, $30.5 \%$; ter, 17.5 ; sue, 35.7 ; oct, 1.8 ; 1 son $\mathrm{B}, 0.8$; liras de 5 vs., 8.5 ; can, 2.4 ; cuartetos hendecasilabos ABAB, $2.6 \%$. 


$\begin{array}{rrlrr}1 & 5.4 \% & \text { rom } & 155 & 29.9 \% \\ 26 & 68.5 \% & \text { oct } & 141 & 11.5 \% \\ & & \text { sil } & 4 & 3 \cdot 3 \% \\ 8 & 3.5 \% & \text { son } & 131 & 3.8 \% \\ 22 & 45.5 \% & \text { ter } & 99 & 18.0 \% \\ 2 & 8.5 \% & \text { lir } & 48 & 7.4 \% \\ 12 & 90.1 \% & \text { sue } & 157 & 19.4 \% \\ 24 & 10.6 \% & \text { can } & 26 & 5.4 \% \\ & & \text { bl. can } & 12 & 5.6 \%\end{array}$

El cambio se nota igualmente en los comienzos y finales de acto. El Cuadro $\mathrm{C}$ da los de 25 de las comedias antiguas (no disponemos de los datos de La destrucción de Conslantinopla). El Cuadro D da las cifras relativas a 25 comedias: los núms. 1-19 de nuestro Cuadro A y los núms. 7, 8 y 10-13 de la Chron., "Table I", esto es, de todas las obras que se pueden fechar con absoluta seguridad en $15^{8} 7^{-1} 59^{6}$.

c o mienzos

$\begin{array}{rr}4 & 4.3 \% \\ 3 & 3.2 \% \\ 44 & 47.3 \% \\ 1 & 1.1 \% \\ 21 & 22.6 \% \\ & \\ 9 & 9.7 \% \\ 11 & 11.8 \% \\ -- & -10- \\ 93 & 100.0\end{array}$

$c o m i e n z o s$

\begin{tabular}{|c|c|c|c|c|}
\hline $4^{8}$ & $64.0 \%$ & red & 41 & $54.7 \%$ \\
\hline 15 & $20.0 \%$ & $\begin{array}{l}\text { qui } \\
\text { rom }\end{array}$ & $\begin{array}{l}5 \\
1\end{array}$ & $\begin{array}{l}6.7 \% \\
1.3 \%\end{array}$ \\
\hline 4 & $5.3 \%$ & oct & 10 & $13.9 \%$ \\
\hline 2 & $2.6 \%$ & ter & 4 & $5.3 \%$ \\
\hline 1 & $1.3 \%$ & lir & & \\
\hline 4 & $5.3 \%$ & sue & 12 & $16.0 \%$ \\
\hline \multirow[t]{2}{*}{ I } & $1.3 \%$ & can. & 1 & $1.3 \%$ \\
\hline & & letrilla & 1 & $1.9 \%$ \\
\hline 75 & 99.9 & & 75 & $99 \cdot 9$ \\
\hline
\end{tabular}

\section{CUADRO C

$$
{ }^{1579^{-1} 5^{86}}
$$

red

qui

oct

son

ter

lir

sue

can

finales

\begin{tabular}{rr}
27 & $29.0 \%$ \\
3 & $3.2 \%$ \\
43 & $46.2 \%$ \\
3 & $3.2 \%$ \\
4 & $4.2 \%$ \\
1 & $1.1 \%$ \\
3 & $3.2 \%$ \\
9 & $9.7 \%$ \\
\hline 93 & 99.9
\end{tabular}

CUADRO D

$15^{8} 7^{-1} 59^{6}$ 
De las 52 comedias del Cuadro A que no se deben a Lope, 19 pertenecen a dramaturgos valencianos - Tárrega, Aguilar, Boyl y Beneyto-, en caso de que el núm. 39 sea de Tárrega. Constituyen así un importante grupo dentro de este período, y, como presentan ciertas divergencias en relación con el estilo de Lope, hay que considerarlas por separado. No incluímos a Guillén de Castro, porque su versificación no se distingue en nada de la de los madrileños.

Según Valbuena Prat (Hist. lit. esp., ed. de 1937, t. 2, p. 256), "se ve que [Tárrega, nacido en 1556 ?,] por la misma cronología era más un prelopista de la anterior generación". Y doña MARía GoYrI de Menéndez Pidal (NRFH, 4, 1950, 352) asegura que, cuando Lope llegó a Valencia en 1588 o 1589 , "el canónigo Tárrega, de más edad, ... ya había compuesto algunas obras dramáticas". La fecha probable del nacimiento de Tárrega, deducida a partir de $\mathbf{1 5 7 5}$ (fecha conocida de su grado de bachiller), lo hace seis años mayor que Lope; no cabe decir, pues, que pertenezca a una generación anterior, sobre todo teniendo en cuenta que Lope empezó a escribir muy temprano (1579?-83). Valbuena encuentra semejanzas entre las obras de Tárrega y las comedias prelopescas, pero la versificación del canónigo es tan típicamente posterior a $15^{87}$ como la de Los hechos de Garcilaso de Lope es típicamente anterior a $15^{84}$. Es posible, por supuesto, que Tárrega haya escrito algunas comedias antes de 1588 o $15^{89}$, pero no tenemos la menor prueba para fundamentar esta hipótesis.

Hay en los valencianos una notable predilección por las quintillas. En tres de las obras de Tárrega hay más redondillas que quintillas (núms. 6, 40 y 41 ), pero en otras cuatro (núms. 32 y $44-46$ ) hay entre $90.5 \%$ y $97.9 \%$ de quintillas, metro del cual aparecen en sus comedias hasta nueve pasajes de 890 versos o más. Del mismo modo, Aguilar escribió más redondillas que quintillas en el núm. 67 , pero $86 \%$ y $90.7 \%$ de quintillas en los núms. 72 y 53 . Beneyto y Boyl muestran la misma preferencia. El máximo de quintillas en las comedias conocidas de Lope es $62.7 \%$ (El ganso de oro, 1588?-95), pero Aguilar tiene todavía $58.3 \%$ en 1608 .

En las comedias de los valencianos escasea el romance. El máxi mo de Tárrega, en sus obras indiscutibles, es 6.2\%, y Aguilar, todavía en 1608 , tiene apenas un $6.7 \%$ de este metro. Más escaso aún es en Boyl y Beneyto. Tampoco abundan los versos italianos. En una comedia de Tárrega (núm. 6) encontramos tres metros italianos, con $9.6 \%$ en total, y en otra (núm. 42) cuatro metros y $12.1 \%$; pero, fuera de ellas, el total de versos italianos va de o a $4.3 \%$, y los tipos de metros de o a 2. En el núm. 73, Aguilar tiene 10\% de sueltos, y en total $15.3 \%$ de versos italianos; pero fuera de este caso, tales versos van de $0.6 \%$ a $9.3 \%$, y los tipos de metros de uno a cuatro. Boyl tiene sólo $4 \%$, y Beneyto 2.1\%. En cambio Lope, 
en las cuatro primeras comedias del Cuadro A, compuestas hacia la época de su primer viaje a Valencia, escribía entre $24.4 \%$ y $35.8 \%$ de versos italianos, en cuatro y cinco metros. ¿Hay alguna razón para creer que los valencianos comenzaran a escribir antes de que Lope visitara su ciudad?

Carlos Boyl, en su "'Romance a un licenciado que deseaba escribir comedias", dice:

De tercetos y de estancias

ha de huir el buen poeta,

porque redondillas sólo

admiten hoy las comedias.

Un romance y un soneto

pide sólo la que es buena.

Por redondillas entiende éstas lo mismo que las quintillas9. Unos pocos versos antes de la cita anterior, encontramos lo siguiente:

y cada jornada tiene

cien redondillas, aunque

son de a diez...

Mérimée creía que el Romance de Boyl se escribió poco después de ${ }_{160}$. Fundándose en esto, en la fecha de El prado de Valencia (ca. 1590) de Tárrega, y en la fecha de 1600 que tiene el ms. de La sangre leal (Cuadro A, núm. 32), construyó una teoría acerca de la evolución de la versificación dramática en Valencia, e intentó fechar de manera aproximada las comedias de Tárrega y Aguilar. Escribe a propósito del canónigo (p. 533):

Les comédies de Tárrega, dès qu'on considère la versification, se partagent en groupes bien tranchés: d'abord, les comédies oì les rhythmes divers se succèdent à bref intervalle, ensuite celles où l'octosyllabe, mêlè à peine de quelques romances, d'un sonnet, d'une rare octave, se déploie en files interminables. El prado de Valencia, La perseguida Amaltea, Las suertes trocadas, La duquesa constante, forment le premier groupe; au second se rattachent les autres comédies du chanoine: La sangre leal, La fundación de la Orden, El cerco de Rodas, La enemiga favorable, El cerco de Pavía, El esposo fingido... Les quatre premières datent du temps où il débutait au théatre; les six dernières de l'époque où son talent essayait de se renouveler.

Cabe objetar desde luego que ni en El prado de Valencia ni en Las suertes trocadas, que tienen respectivamente un pasaje de 1236 vs. y otro de 1388 en redondillas, encontramos esos "rhythmes divers"

${ }^{8}$ Publicado en la BAAEE, t. 43, pp. xxvi-xxvii, y en JuLıÁ, t. 1, pp. 627629. Cf. BHi, 8 (19o6), 163-171.

'Cf. Lope de Vega, Peribánez, ed. Ch.V. Aubrun y J. F. Montesinos, p. xlviii, nota 2. 
que "se succèdent à bref intervalle" a lo largo de la obra; y que $L a$ perseguida Amaltea, con sus cinco pasajes de redondillas, seis de quintillas y un soneto, queda mucho mejor en el segundo grupo de Mérimée que en el primero. La duquesa constante, con veintiocho pasajes de siete metros, es la única comedia que se ajusta estrictamente a lo que Mérimée considera la primera manera de Tárrega; su pasaje más largo es uno de $44^{\circ}$ vs. en quintillas (acto II). En cuanto a Aguilar, dice Mérimée lo siguiente (pp. 537-538):

... à Valencia, la versification de la comedia, cette versification que l'on a coutume d'étudier en dehors du temps et de l'espace, a lentement évolué. D'une complexité qui lui venait de la tragédie, elle a passé, aux environs de l'année I6oo, à l'uniformité de l'octo. syllabe rimé, à peine entremêlé de quelques autres rhythmes, puis par une autre réaction elle s'est annexé des strophes variées, dont la plupart ont ce trait commun qu'elles mettent en ceuvre, à coté de l'hendécasyllabe, son vers quebrado ou heptasyllabe. Dès lors, la comedia ne se refusera plus aucune fantaisie.

Mérimée divide también las obras de Aguilar en dos grupos. En el primero pone La gitana melancólica, La venganza honrosa, La fuerza del interés, La nuera humilde y El mercader amante; en el segundo, Los amantes de Cartago, La suerte sin esperanza ${ }^{\mathbf{1 0}}$, Fray Luis Bertrán y El gran patriarca ${ }^{11}$. También aquí cabe objetar que Lavenganza honrosa ${ }^{12}$, con sus actos II y III totalmente en quintillas, dista mucho de ajustarse a los requisitos imaginados por Mérimée para las comedias valencianas del primer período. Por otra parte, La nuera humilde contiene una canción, forma estrófica que, según Mérimée, no aparece hasta después de 1600; esta última comedia tiene sólo cuatro metros, en contraste con los seis de Los amantes de Cartago, y casi el doble de versos de romance; así, pues, La nuera parecería posterior a Los amantes.

En lo que evidentemente acierta Mérimée es en asignar una fecha tardía a El cerco de Pavia y El cerco de Rodas, pues contienen el mayor porcentaje de romance de todas las obras auténticas de Tárrega, y consta que los valencianos fueron muy lentos para adoptar este metro en cualquier cantidad. Los dos Cercos son poco variados en cuanto a versificación, y se asemejan en esto a $\mathrm{El}$ marido asegurado de Boyl. Así, pues, Mérimée puede estar en lo justo en cuanto a la evolución de Tárrega. En cuanto a Aguilar, la única de sus comedias que sólo tiene tres metros es La venganza honrosa. Si las afirmaciones de Boyl en su Romance expresan algo más que una

${ }^{10}$ Publicada en Norte (1616); por su versificación, parece de los mismos años que $E l$ gran patriarca.

${ }^{11}$ Publ. también en Norte; como el "patriarca" murió en 1611, la fecha es 1611-16. Cf. Mérimée, p. 520 .

${ }_{12}$ Publ. en Flor (1615). Por su versificación, no parcce posterior a 1600. 
simple preferencia personal, la situación era muy distinta en Valencia y en Madrid. En Madrid encontramos comedias de fecha antigua con pocos metros (núms. 5, 14, 18), comedias con muchos metros no sólo en 1596-97 (núms. 15, 17, 20), sino también en 1600 (núms. 34-36) y probablemente hacia 1602 (núm. 57), y además comedias con pocos metros entre 1603 y 1610 (núms. 58, 81, 84). No es posible, pues, suponer una tendencia determinada en las comedias madrileñas de $1590-1600$, excepto que poco a poco aumenta la variedad de formas de versificación. Fue una época de experimentación métrica, encabezada en la Corte por el fecundo Lope.

Parece cierto que Aguilar empezó a escribir "quebrados" (llamados "canción" en la Chronology y en el presente artículo) hacia 1600 , y que Tárrega, muerto en 1602 , nunca usó este metro en sus comedias. En cambio, en Lope se hallan 27 casos entre 1587 y 1603 .

En un palabra, Mérimée formuló una ingeniosa teoría sobre la cronología de la comedia valenciana en una época en que se sabía poco acerca de la versificación de aquel período. Como los valencianos diferían de sus contemporáneos madrileños en su empleo de las quintillas, del romance y de los hendecasílabos, la teoría puede ser acertada; pero en realidad no poseemos bastantes datos seguros sobre las comedias valencianas para aceptar o rechazar la teoría.

El Cuadro E da el número de comedias que contienen cada uno de los metros, y el porcentaje del total, en Lope, en sus contemporáneos madrileños (incluyendo a Guillén de Castro) y en los valencianos.

El Cuadro $\mathrm{F}$ da los porcentajes más elevados que llega a tener cada metro en Lope, en sus contemporáneos madrileños (Castro inclusive) y en los valencianos.

GUADRO E

$$
1587-1610
$$

\begin{tabular}{|c|c|c|c|c|c|c|}
\hline \multicolumn{2}{|c|}{$\begin{array}{l}\text { Lope } \\
\text { comedias }\end{array}$} & \multicolumn{2}{|c|}{$\begin{array}{l}\text { madrileños } \\
33 \text { comedias }\end{array}$} & & \multicolumn{2}{|c|}{$\begin{array}{l}\text { valencianos } \\
\text { Ig comedias }\end{array}$} \\
\hline 131 & $100 \%$ & 33 & $100 \%$ & red & 16 & $84 \%$ \\
\hline 120 & $91 \%$ & 26 & $79 \%$ & qui & 18 & $94 \%$ \\
\hline 19 & $16 \%$ & 8 & $24 \%$ & déc & 1 & $5 \%$ \\
\hline 109 & $83 \%$ & 29 & $88 \%$ & rom & 17 & $89 \%$ \\
\hline 119 & $91 \%$ & 15 & $45 \%$ & oct & 7 & $37 \%$ \\
\hline 103 & $79 \%$ & 22 & $66 \%$ & son & 6 & $31 \%$ \\
\hline 80 & $61 \%$ & 19 & $39 \%$ & ter & 6 & $31 \%$ \\
\hline 41 & $31 \%$ & 7 & $21 \%$ & $\operatorname{lir}$ & & \\
\hline 126 & $96 \%$ & 24 & $73 \%$ & sue & 7 & $37 \%$ \\
\hline $29^{13}$ & $22 \%$ & 5 & $15 \%$ & can & 4 & $21 \%$ \\
\hline
\end{tabular}

${ }^{13}$ Aquí se incluye bl. can. además de can. 


$\begin{array}{rrlr}\text { Lope } & \text { madrileños } & & \text { valencianos } \\ 97.9 \% & 95.8 \% & \text { red } & 91.7 \% \\ 62.7 \% & 63.1 \% & \text { qui } & 97.9 \% \\ 11.7 \% & 3.8 \% & \text { déc } & 1.0 \% \\ 29.9 \% & 28.7 \% & \text { rom } & 6.7 \% \quad(11.9 \%)^{14} \\ 13.8 \% & 8.8 \% & \text { oct } & 7.6 \% \\ 3.8 \% & 2.5 \% & \text { son } & 0.6 \% \\ 18.0 \% & 9.1 \% & \text { ter } & 5.3 \% \\ 7.4 \% & 2.0 \% & \text { lir } & \\ 14.0 \% & 19.4 \% & \text { sue } & 10.0 \% \\ 5.4 \% & 4.3 \% & \text { can } & 2.7 \%\end{array}$

Un hecho que se deduce nítidamente del Cuadro E es que Lope escribió más versos italianos, en un número proporcionalmente mayor de comedias, que los demás poetas de esa época. Octavas y sueltos aparecen en más del $90 \%$ de sus comedias. Entre los valencianos, no hay un solo metro italiano en más del $40 \%$ de las comedias, y entre los demás poetas, sólo los versos sueltos y los sonetos se dan en más del $50 \%$ de las obras. Por otra parte, cuando los metros italianos aparecen en los otros madrileños (Cuadro F), los porcentajes no son muy inferiores a los de Lope, excepto en lo que toca a los tercetos y a las liras. De hecho, una comedia de Salustio (núm. 94) iguala el máximo porcentaje de sueltos de Lope, y una de Grajal (núm. 92) lo excede, aunque por muy pocos versos.

Nuestro último cuadro ofrece en forma más clara una prueba de la afición de Lope al hendecasílabo. Muestra el número de comedias que contienen de seis metros italianos (el máximo) a cero.

\section{CUADRO G}

Número de metros italianos en una comedia $\begin{array}{lllllllll}6 & 5 & 4 & 3 & 2 & 1 & \text { o }\end{array}$

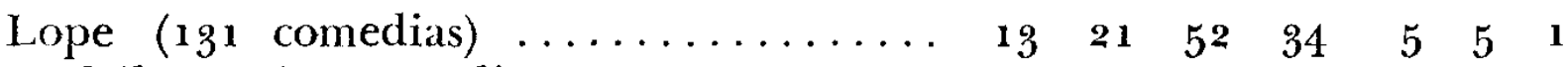
$\begin{array}{llrrrrrr}\text { madrileños }(33 \text { comedias }) & \ldots \ldots \ldots \ldots \ldots \ldots & 3 & 3 & 12 & 11 & 3 & 1 \\ \text { valencianos }(19 \text { comedias }) & \ldots \ldots \ldots \ldots \ldots & & 2 & 3 & 3 & 8 & 3\end{array}$

Entre los valencianos, el núm. 6 tiene el máximo porcentaje de octavas, o sea $7.6 \%$, pero ninguna otra comedia llega a más del $3.7 \%$ que tiene el núm. 41. Entre los contemporáneos madrileños, el núm. 91 tiene el máximo, $8.8 \%$, pero el núm. 66 , que le sigue inmediatamente a este respecto, tiene ya sólo $5.5 \%$. En cambio, hay quince comedias de Lope con más de $9 \%$ (cf. Chron., pp. 403-404). La mayor afición de Lope a los versos italianos puede explicarse por el hecho de que comenzó a escribir hacia 1580 , cuando estaban de

${ }^{14}$ El porcentaje entre paréntesis es del dudoso núm. 39 . 
moda, mientras que los demás poetas comenzaron evidentemente hacia 1590, cuando los metros españoles tenían la preferencia.

Los contemporáneos madrileños escribieron romances en un número de comedias proporcionalmente mayor que Lope, y los valencianos emplearon ese metro casi en todas sus comedias, aunque en pequeño porcentaje. Aquí también, la razón principal parece ser que, entre las obras más antiguas del período estudiado, son más las comedias de Lope que las de los otros madrileños: veintiuna comedias sin romance son anteriores a 1604 , y la otra es de este año. El porcentaje máximo de Castro es 14.4; Salustio, Valdivielso, Castellano (núms. 69, 79, 89) y Mira de Amescua en tres piezas (núms. 62, 82,84 ) llegan a $20 \%$ o más, pero Vélez de Guevara, en el núm. 96 , es el único que se acerca al porcentaje máximo de Lope.

También el empleo de las décimas es más frecuente, proporcionalmente, en los otros madrileños que en Lope, por la misma razón apuntada para los romances. El porcentaje más elevado de Lope $(11.7 \%$ ) es muy superior al de ellos, pero se encuentra en una sola obra (núm. 85), y a ésta sigue, muy de lejos, Del mal lo menos (1604?-o9), con sólo $5 \%$ de décimas.

En 1596, Lope concluyó el acto II del Marqués de Mantua con un romance. En este metro terminan, hacia la misma época, los actos II y III de La serrana de la Vera. En él terminan, en 1604?-o6, los tres actos de El secretario de si mismo, y a partir de entonces, con ciertas excepciones, Lope tiende cada vez más a terminar los actos en ese metro. Los demás madrileños lo imitan. A partir de 1599, las siguientes comedias acaban el acto III en romance: núms. 26, 39, $49,62,66,77,79,80,81,82,84,89,95$ y 96 ; en cuatro de ellas (núms. $79,81,89$ y 96 ) son dos los actos que acaban en romance.

Lo dicho en estas páginas corrobora, pues, lo que hasta ahora ha sido mera probabilidad: que, por lo menos hasta el año 1611 , el genio fecundo de Lope encabezó y encauzó no sólo la evolución del género, sino también la de su versificación. El examen de las cincuenta y dos obras escritas por sus contemporáneos fundamenta la opinión que algunos hemos sostenido desde i940, a saber, que las comedias en que hay un fuerte porcentaje de romance, de décimas o de silvas, no se escribieron en la primera década del siglo xviI, sino muchos años después ${ }^{15}$.

† Courtney Bruerton

${ }^{15}$ Por ejemplo, en Alarcón: La cueva de Salamanca, rom 35.8\%; La culpa busca la pena, rom $45.8 \%$; La manganilla de Melilla, rom $33.2 \%$. En Guillén de Castro: Cuanto se estima el honor, rom $32.4 \%$, déc $11.7 \%$; Dido y Eneas, rom $33.7 \%$. En Tirso de Molina: La gallega Mari-Hernández, rom $47.4 \%$, sil $5.2 \%$; Los lagos de San Vicente, sil 9\%; El Aquiles, déc 23\%. Atribuida a Tirso: La joya de las montañas, rom $64.2 \%$. 